\title{
Development of Effective empirical potentials for molecular dynamics simulations of the structures and properties of boroaluminosilicate glasses
}

\author{
Lu Deng ${ }^{1}$ and Jincheng $\mathrm{Du}^{1, *}$ \\ ${ }^{1}$ Department of Materials Science and Engineering, University of North Texas, Denton, Texas, \\ U.S.A. \\ (*Corresponding author. Email: $\underline{\text { du@unt.edu })}$
}

\begin{abstract}
A set of empirical potentials have been developed to enable molecular dynamics simulations of oxide glasses with the most common glass formers: silica, boron and aluminum oxides. Built upon the recent borosilicate potentials, this set of partial charge effective potentials feature compositionally dependent variable atomic charges and pairwise short range interactions that ensure high computational efficiency. They can correctly reproduce the short range structure features of boroaluminosilicate glasses including $\left[\mathrm{SiO}_{4}\right]$ tetrahedral network, aluminum coordination, and, importantly, the coordination change of boron as a function of composition. By using the newly developed potentials, a series of sodium boroaluminosilicate glasses were simulated and the structures analyzed in terms of bond distance, bond angle, and coordination number, which were compared with available theoretical, simulation and experimental results. Structural analysis such as polyhedral connectivity analysis, $\mathrm{Q}^{\mathrm{n}}$ analysis, and ring size distribution were obtained to investigate the medium range structure features of these glasses. Furthermore, mechanical properties such as Young's, shear and bulk moduli were calculated and were found to be in good agreement with experimental data. The vibrational density of states was also calculated and compared with previous MD and ab initio results. The results show ${ }^{[3]} \mathrm{B}$ and ${ }^{[4]} \mathrm{B}$ had distinctive spectra features and vibrational spectra were in good agreement with earlier ab initio studies.
\end{abstract}




\section{Introduction:}

Boroaluminosilicate glasses find wide applications in technological and industrial fields such as nuclear waste disposal, sealing materials for fuel cells, chemical and heat-resistant glass containers (such as the Pyrex ${ }^{\circledR}$ glasses), optical components, and insulating fiber glasses ${ }^{1,2,3,4}$. However, as compared to silicate glasses, the structures of these glasses are more complex due to interactions of multiple glass formers including $\mathrm{SiO}_{2}, \mathrm{~B}_{2} \mathrm{O}_{3}$ and $\mathrm{Al}_{2} \mathrm{O}_{3}$, as well their interactions and competition for modifier cations and oxygen ions. These complex interactions lead to the known mixed glass former effect ${ }^{5}$. The lack of detailed structural information hinders the understanding the composition-structure-property relationship hence the rational design of these glasses for various applications. In this paper, we aim to develop a set of effective compositional dependent partial charge potentials that enable molecular dynamics simulations of these glasses to account for the interaction of multi glass former and accurately predict both the structure and properties of these glasses with many practical industrial and technological applications.

Addition of boron oxide and aluminum oxide to silicate glasses leads to complex competition of alkali cations and the intriguing mixed glass former effect. It is known that introduction of alkali oxide to silica results in the breaking the $\mathrm{Si}-\mathrm{O}-\mathrm{Si}$ linkages and the three dimensional network by the formation of non-bridging oxygen (NBO). When alkali oxide is added to borosilicate glasses, however, there is a competition between the formation of NBOs on $\left[\mathrm{SiO}_{4}\right]$ tetrahedrons and conversion of boron from 3- to 4 -coordination state $\left({ }^{[3]} \mathrm{B}\right.$ to $\left.{ }^{[4]} \mathrm{B}\right)$, which can be described by a two-state statistical model with difference in enthalpy of the two process ${ }^{6}$. In sodium aluminosilicate glasses, especially those peralkali compositions, aluminum ions mainly exist in 4-coordination state and sodium ions play a charge compensation role ${ }^{7}$. When the three glass formers coexist in boroaluminosilicate glasses, addition of alkali oxide modifiers can play multiple competing roles including charge compensation of $\left[\mathrm{AlO}_{4}\right]^{-}$, conversion of ${ }^{[3]} \mathrm{B}$ to ${ }^{[4]} \mathrm{B}$, and creating $\mathrm{NBO}$ on $\left[\mathrm{SiO}_{4}\right]^{4,8}$. It is generally believed that the enthalpy of formation increases in the three competing processes ${ }^{6,8}$. As a result, the empirical potential for boroaluminosilicate glasses needs to properly describe the three competing processes.

Solids state NMR results have shown that the ${ }^{[3]} \mathrm{B}$ to ${ }^{[4]} \mathrm{B}$ conversion is the structural origin of the boron anomaly behaviors in a number of properties such as glass transition temperature, coefficient of thermal expansion and density of borate glasses ${ }^{9}$, where the structure of borate 
glasses is characterized by $\mathrm{R}=\left[\mathrm{Na}_{2} \mathrm{O}\right] /\left[\mathrm{B}_{2} \mathrm{O}_{3}\right]$ and the fraction of ${ }^{[4]} \mathrm{B}$ and consequently the properties show a maximum at around $\mathrm{R}=0.4$. In borosilicate glasses, the trend is preserved but the maximum $\mathrm{R}$ value varies with $\mathrm{K}=\left[\mathrm{SiO}_{2}\right] /\left[\mathrm{B}_{2} \mathrm{O}_{3}\right]$; thus both $\mathrm{R}$ and $\mathrm{K}$ are important parameters to characterize the borosilicate glasses. Yun and Bray ${ }^{10}$ proposed a model for sodium borosilicate glasses to calculate the four coordinated boron percentage $\left(\mathrm{N}_{4}\right)$ with different $\mathrm{R}$ and $\mathrm{K}$ values based on NMR studies, and later modified and improved by Dell and Bray ${ }^{11}$. In the boroaluminosilicate glasses, the addition of alumina creates competition of between boron and aluminum for oxygen and charge compensating alkali ions. For example, it is generally accepted that addition of aluminum ions will reduce the excess sodium content which changes the $\mathrm{N}_{4}$ value $^{4}$. NMR studies ${ }^{12}$ showed that the experimental $\mathrm{N}_{4}$ value in sodium boroaluminosilicate glasses is smaller than those in sodium borosilicate glasses with same $\left(\left[\mathrm{Na}_{2} \mathrm{O}\right]-\left[\mathrm{Al}_{2} \mathrm{O}_{3}\right]\right) /$ $\left[\mathrm{B}_{2} \mathrm{O}_{3}\right]$ and $\mathrm{K}$ values. The reason of the lower $\mathrm{N}_{4}$ value in sodium boroaluminosilicate glass is that the sodium oxide is firstly used to convert aluminum from higher coordination states and $\mathrm{Na}^{+}$ions charge compensate $\left[\mathrm{AlO}_{4}\right]^{-}$. Du and Stebbins ${ }^{8}$ proposed a modification of the Yun, Dell and Bray model (YDB model) ${ }^{10,11}$ where the $\mathrm{R}$ and $\mathrm{K}$ values in original YDB model are replaced by $R^{\prime}=\left[\mathrm{Na}_{2} \mathrm{O}\right] /\left(\left[\mathrm{B}_{2} \mathrm{O}_{3}\right]+\left[\mathrm{Al}_{2} \mathrm{O}_{3}\right]\right)$ and $\mathrm{K}^{\prime}=\left[\mathrm{SiO}_{2}\right] /\left(\left[\mathrm{B}_{2} \mathrm{O}_{3}\right]+\left[\mathrm{Al}_{2} \mathrm{O}_{3}\right]\right)$, since boron and aluminum have similar behavior of mixing. This new model is designed for compositions for sodium boroaluminosilicate glasses that sodium concentration is higher than that of aluminum. In this model, $\left[\mathrm{Na}_{2} \mathrm{O}\right]-\left[\mathrm{Al}_{2} \mathrm{O}_{3}\right]$ defines the practically available quantity of the sodium for ${ }^{[3]} \mathrm{B}$ to ${ }^{[4]} \mathrm{B}$ conversion and $\mathrm{NBOs}$ for $\mathrm{SiO}_{4}$ tetrahedrons. Although this model works well for most compositions, it has limitations in compositions with $\left[\mathrm{Al}_{2} \mathrm{O}_{3}\right] \gg>\left[\mathrm{B}_{2} \mathrm{O}_{3}\right]$, since the $\mathrm{N}_{4}$ is incorrectly predicted to be 1 when the $R^{\prime}$ value is larger than 1 . Molecular dynamic (MD) simulations have been an important method to study the structures of glass and amorphous materials since its first application about four decades ago ${ }^{5}$. Among other factors, the interatomic potential plays a key role in MD simulations. Although there are many suitable potentials for silicate glasses, potentials that are capable of simulating borate and aluminate glasses are limited. It is especially challenging for borate containing silicate and aluminate glasses due to the interaction of the glass formers, or, the mixed glass former effect. There are several attempted potentials for multicomponent glasses. Among these potentials, only a few of them contain boron oxide and none of them can fully study the structures of boroaluminosilicate compositions. For example, Delaye and Cormier ${ }^{13,14}$ proposed a set of potential which can be 
applied to the systems containing $\mathrm{Na}, \mathrm{B}, \mathrm{Al}, \mathrm{Si}, \mathrm{O}, \mathrm{Zr}$ and $\mathrm{Ca}$ using the combination of two and three body potential terms. However, this potential produces glasses with over-estimated four coordinated boron, since the $\mathrm{N}_{4}$ values in boroaluminosilicate glass should be less than the ones in sodium borosilicate glasses based on El Damrawi's work ${ }^{12}$; moreover, the BMH potential form has a limitation of representing exact values of electron charge. Huang and Kieffer ${ }^{15,16}$ proposed a coordination dependent potential set which include the charge transfer effects. However, the potentials were developed for silica and boron oxide only, and the potential form is relatively complex. Du and Cormack ${ }^{17,18}$ employed partial charge to describe partial covalence of bonds in certain system and develop a potential which can describe the systems which contains $\mathrm{Si}, \mathrm{Na}, \mathrm{O}, \mathrm{P}^{19}$, rare earth ions ${ }^{20}$, and $\mathrm{Al}^{7}$. However, boron is not included in this potential. Pedone and coworkers ${ }^{21}$ proposed a potential set which can deal with alkali and alkali earth silicate and aluminate glasses but boron oxide is not included in this potential set. There are several potentials that were developed to describe borate or borosilicate glasses. These potentials have a general feature that is to take the local coordination environment into consideration for boron charge or B-O interactions, only through which the boron coordination change with composition can be described by the potentials. For example, Park and Cormack proposed a set of coordination dependent potential for borate and borosilicate glasses ${ }^{22}$. Depending on the coordination number, different parameters, were used for 3- and 4-coordinated boron atoms. Huang and Kieffer $^{16}$ proposed a set of charge transfer potential for boron oxide glass where the atomic charge is allowed redistribute depending on the local environment during the simulations. However, this potential was developed only for $\mathrm{B}_{2} \mathrm{O}_{3}$ and it has a complicated form and relatively high computational cost. Inoue et $\mathrm{al}^{23}$ developed a set of partial charge pairwise potential for sodium borosilicate glasses and it was shown to be able reproduce boron coordination change with composition. Kieu and coworkers ${ }^{24}$ recently developed a set of composition dependent variable charge pair-wise potential for sodium borosilicate glasses which were shown to have high computational efficiency and can reproduce the structural information and mechanical properties of sodium borosilicate glasses. Boron coordination change with composition was addressed by the variation of atomic charge on boron and other ions, as well as the repulsion term of the short range B-O interactions. Alumina is not included in this potential set, however, which prevents us from the simulations of common glass composition of the boroaluminosilicate system. 
In addition to classical MD simulations, several ab initio MD or first principles calculations were used to study boron oxide or borosilicate glasses. These results provide input from first principles and valuable comparison for empirical potential development. Ferlat et al ${ }^{25}$ studied boron oxide glasses using ab initio MD simulations, in which two numerical models containing boroxol ring units have been tested. Structural and vibrational properties have been investigated and compared with experimental data from static structure factor, NMR and Raman. More recently, Kob and co-workers ${ }^{26,27}$ studied sodium borosilicate glasses for both liquid and glass states using ab initio MD. Static and dynamic properties of liquid state such as partial structure factor, boron coordination and diffusion behavior have been studied. Furthermore, radial distribution, sodium distribution around ${ }^{[3]} \mathrm{B}$ and ${ }^{[4]} \mathrm{B}$, total electronic density of states and vibrational density of states have been analyzed for the glass state. In addition, average boron charge on oxygen atoms, dielectric function and absorption spectra give insight into understanding the sodium borate glass system.

In this paper, we've developed a set of compatible and effective potential for simulating sodium boroaluminosilicate glass systems based on the framework for sodium borosilicate systems proposed by Kieu et $\mathrm{al}^{24}$. After extensive testing and addressing some limitations of the original potential, aluminum related parameters were developed by empirical fitting and applied several series of boroaluminosilicate glasses. Detailed short and medium range structure characterization of the glasses and calculations of mechanical and vibrational properties are then presented.

\section{Methodologies:}

\subsection{Empirical potentials for borosilicate glasses}

Kieu and coworkers ${ }^{24}$ developed a set of potential for sodium borosilicate glasses based on earlier development of partial charge empirical potentials for silicate magma and minerals by Guillot et al $^{28}$. Similar to several of the potentials for silicates ${ }^{18,29,30}$, this set of potential combines a long range coulomb term and a short range Buckingham term:

$\Phi\left(r_{i j}\right)=\frac{q_{i} q_{j}}{r_{i j}}+A_{i j} e^{\frac{-r_{i j}}{\rho_{i j}}}-\frac{C_{i j}}{r_{i j}{ }^{6}}$

where, $r_{i j}$ is the interatomic distance between atom $\mathrm{i}$ and $\mathrm{j} ; q_{i}$ and $q_{j}$ are the effective charge for atom $\mathrm{i}$ and $\mathrm{j}$, respectively. $A_{i j}, \rho_{i j}$ and $C_{i j}$ are the parameters for the Buckingham term. 
One essential component of the Kieu et al potential ${ }^{24}$ is the compositional dependent variable atomic charges. The charges of boron, and consequently all other elements, vary with two ratios are commonly employed in describing the structures of borosilicate glasses: $R=\frac{\mathrm{Na}_{2} \mathrm{O}}{\mathrm{B}_{2} \mathrm{O}_{3}}$ and $K=\frac{\mathrm{SiO}_{2}}{\mathrm{~B}_{2} \mathrm{O}_{3}}$. Two assumptions were made on the atomic charges: Firstly, the ratio of atomic charge between 3- and 4-coordinated boron, and those between the two boron species and oxygen remain constant: $\frac{q_{B_{4}}}{q_{B_{3}}}=1.14, \frac{q_{B_{4}}}{q_{O}}=-1.71, \frac{q_{B_{3}}}{q_{O}}=-1.5$. This is based on the results of quantum mechanical calculations of lithium borate system ${ }^{31}$ and molecular dynamics simulation result of $\mathrm{B}_{2} \mathrm{O}_{3}$ glass $^{16}$. Secondly, the average boron charge is determined by $\left|\frac{q_{B}^{\prime}}{q_{O}^{\prime}}\right|=f_{B_{3}}\left|\frac{q_{B_{3}}}{q_{O}}\right|+$ $f_{B_{4}}\left|\frac{q_{B_{4}}}{q_{O}}\right|$, where $f_{B 3}$ and $f_{B 4}$ are the fraction of 3- and 4-coordinated boron based on the YDB model $^{10,11}$ that was originated from solid state NMR studies. Based on these assumptions, the average boron to oxygen charge ratio as a function of $\mathrm{R}$ is fitted to those from YDB model. As a result, the charge of boron and other elements can be calculated by solving following two equation:

$q_{B}^{\prime}=-q_{o}^{\prime}\left(C_{6} \mathrm{~K}^{2}+\sum_{i=1}^{5} C_{i} \mathrm{R}^{i}+C_{0}\right)$

$q_{i}^{\prime}=q_{i}-N_{B} \frac{q_{B}^{\prime}-q_{B}}{N_{S i}+N_{O}+N_{N a}} \quad$ where $i=S i, O, N a$

Where, $C_{i}(i=0,1,2, \ldots, 6)$ are empirical parameters, $N_{i}(i=B, N a, S i, O)$ are atom numbers of each element, and $q_{i}(i=B, N a, S i, O)$ are the initial charge values from Guillot-Sator's paper ${ }^{28}$ with the values being $-0.945,1.89,0.4725$ for $\mathrm{O}, \mathrm{Si}$ and $\mathrm{Na}$, respectively.

In addition to compositional dependent charges, this potential set also has an adjustable "A" parameters for the B-O Buckingham potential, and the ratios $\mathrm{R}$ and $\mathrm{K}$ are also involved in " $\mathrm{A}$ " parameter determination for B-O pair obtained by equation 4:

$A_{B-O}=\sum_{i=1}^{5} a_{i} R^{* i}+a_{0}$

where, $a_{i}(\mathrm{i}=0,1,2, \ldots, 5)$ are empirical values and $\mathrm{R}^{*}$ is defined by both $\mathrm{R}$ and $\mathrm{K}$ values through following equation: 
$R^{*}=\left\{\begin{array}{lr}\min \left(R, \frac{K}{16}+0.5\right), & R<\frac{K}{4}+0.5 \\ 0, & R \in\left(\frac{K}{4}+0.5, K+2\right)\end{array}\right.$

It is worth mentioning that there exists a discontinuity of $\mathrm{R}^{*}$ value when $\mathrm{R}$ equals to $\mathrm{K} / 4+0.5$, which will also affect boron $\mathrm{N}_{4}$ values.

\subsection{Addition of aluminum to the borosilicate potentials}

\subsubsection{Assumptions for adding $\mathrm{Al}_{2} \mathrm{O}_{3}$}

Alumina is a common component that improves the chemical durability and mechanical strength of glasses. From structure point of view, addition of $\mathrm{Al}_{2} \mathrm{O}_{3}$ to borosilicate glasses introduces competition for oxygen and charge compensation alkali ions with boron. In order to include $\mathrm{Al}^{3+}$ related parameters to the sodium borosilicate potential, ${ }^{24}$ we added a new ratio

$H=\frac{\mathrm{Al}_{2} \mathrm{O}_{3}}{\mathrm{~B}_{2} \mathrm{O}_{3}}$ so that both charge and $\mathrm{A}$ value of B-O Buckingham pair can vary while $\mathrm{Al}$ composition changes. Moreover, based on the model proposed by Du and Stebbins ${ }^{8}$, the YDB model $^{10,11}$ for borosilicate glasses can be applied to boroaluminosilicate glasses by modifying $\mathrm{R}$ and K values. Since the network forming behavior of 4-coordinated aluminum, which is the majority coordination species in these glasses, is quite similar to 4-coordinated boron, these two species are considered as one general type. As a result, the modified $\mathrm{R}$ value called $R^{\prime}$ is introduced and defined as shown below:

$R^{\prime}=\frac{N a_{2} \mathrm{O}}{\mathrm{B}_{2} \mathrm{O}_{3}+\mathrm{Al}_{2} \mathrm{O}_{3}}$

The modified $\mathrm{K}$ value called $K^{\prime}$ is then defined as:

$K^{\prime}=\frac{\mathrm{SiO}_{2}}{\mathrm{~B}_{2} \mathrm{O}_{3}+\mathrm{Al}_{2} \mathrm{O}_{3}}$

The new ratio $\mathrm{N}_{4}$ ' that describes four-coordinated boron can be expressed in the following equation:

$N_{4}^{\prime}=\frac{N_{4} \times B_{2} O_{3}+A_{2} O_{3}}{B_{2} O_{3}+A l_{2} O_{3}}$

Additionally, we realize that the $\mathrm{R}^{*}$ value plays the similar role comparing with the $\mathrm{N}_{4}$ value of the systems in the original Kieu's potential in the low sodium content region $\left(R<\frac{K}{4}+0.5\right)$. Furthermore, for those systems with $K^{\prime}$ larger than 8 , YDB model of high silicon content $(\mathrm{K}>8)^{10}$ 
is employed to deal with the problem that $\mathrm{N}_{4}$ is higher than 1 . This will be useful while dealing with the systems which has high silicon together with low boron content. As a result, by modifying equation 5 , the $\mathrm{R}^{* \prime}$ value is calculated from equation 9:

$$
\mathrm{R}^{*^{\prime}}=\left\{\begin{array}{lc}
\min \left(R^{\prime}, \frac{K^{\prime}}{16}+0.5\right), & R^{\prime} \leq \frac{K^{\prime}}{4}+0.5, K^{\prime} \leq 8 \\
0, & R^{\prime} \in\left(\frac{K^{\prime}}{4}+0.5, K^{\prime}+2\right), K^{\prime} \leq 8 \\
R^{\prime} & R^{\prime} \leq 1, K^{\prime}>8 \\
0 & R^{\prime}>1, K^{\prime}>8
\end{array}\right.
$$

According to recent NMR studies of boroaluminosilicate glasses ${ }^{12}$, it is shown that sodium ions first convert aluminum from 5-6 to 4-coordination, then the remaining sodium ions convert boron from 3 to 4-coordination. Therefore, those compositions with higher $\mathrm{Al}_{2} \mathrm{O}_{3}$ than $\mathrm{Na}_{2} \mathrm{O}$ will give a $N_{4}$ value which equal to 0 . In addition, the smallest value of $\mathrm{R}^{* \prime}$, which may obtain a non-negative $N_{4}$ value, is equal to $H^{\prime}\left(H^{\prime}=\frac{A l_{2} O_{3}}{B_{2} O_{3}+A l_{2} O_{3}}\right)$. As a result, the effective $\mathrm{R}^{*}$ value, which is called $\mathrm{R}_{e}^{*}$, will be applied to calculate the A parameter of B-O pair instead of $R^{*}$ in equation 4. This variable is the $\mathrm{N}_{4}$ value (i.e. the fraction of four-coordinated boron) based on the Du and Stebbins model ${ }^{8}$ and can be calculated through equation 10:

$$
\mathrm{R}_{e}^{*}=\left\{\begin{array}{lc}
\frac{\left[\mathrm{R}^{* \prime} \times\left(\mathrm{Al}_{2} \mathrm{O}_{3}+\mathrm{B}_{2} \mathrm{O}_{3}\right)-\mathrm{Al}_{2} \mathrm{O}_{3}\right]}{B_{2} \mathrm{O}_{3}} & R \geq H, \mathrm{R}^{*^{\prime}} \geq H^{\prime} \\
0 & R \geq H, \mathrm{R}^{* \prime}<H^{\prime} \\
& R<H
\end{array}\right.
$$

The charge determination equations were also modified based on the Du and Stebbins model $^{8}$. Furthermore, since sodium ions preferentially bond to aluminum and then boron, the amount of sodium which will affect boron charge is more accurately defined as:

$$
R_{e}^{\prime}=R^{\prime}-H^{\prime}=\frac{\mathrm{Na}_{2} \mathrm{O}-\mathrm{Al}_{2} \mathrm{O}_{3}}{\mathrm{~B}_{2} \mathrm{O}_{3}+\mathrm{Al}_{2} \mathrm{O}_{3}}
$$

Notice that if the aluminum concentration is higher than that of sodium, this value will become 0 . Therefore, the charge values of each element can be obtained by solving following two equations:

$$
q_{B}^{\prime}=-q_{o}^{\prime}\left(C_{6} K^{\prime 2}+\sum_{i=1}^{5} C_{i} R_{e}^{\prime i}+C_{0}\right)
$$


$q_{i}^{\prime}=q_{i}-N_{B} \frac{q_{B}^{\prime}-q_{B}}{N_{N a}+N_{A l}+N_{S i}+N_{O}} \quad$ where $i=N a, A l, S i, O$

Where, $C_{i}(i=0,1,2, \ldots, 6)$ are empirical parameters which also are given in Table $1, N_{i}(i=$ $B, N a, A l, S i, O)$ are atom numbers of each element, and $q_{i}(i=B, N a, A l, S i, O)$ are the initial charge values from Guillot-Sator's paper ${ }^{28}: q_{B}=1.4175 ; q_{N a}=0.4725 ; q_{A l}=1.4175 ; q_{S i}=$ $1.89 ; q_{0}=-0.945$.

Table 1 Empirical parameters in Eqs. 4 and 12 based on Kieu et al ${ }^{24}$.

\begin{tabular}{cccccccc}
\hline & 0 & 1 & 2 & 3 & 4 & 5 & 6 \\
\hline $\mathrm{a}_{\mathrm{i}}$ & 180390.53 & 47166.67 & -43827.65 & 210268.55 & -52520.42 & -139041.69 & ------ \\
$\mathrm{C}_{\mathrm{i}}$ & 1.49643 & 0.29504 & -0.2565 & 0.08721 & -0.01323 & 0.00073 & $0.0\left(R_{e}^{\prime} \leq 0.5+K^{\prime} / 16\right)^{\mathrm{a}}$ \\
& & & & & & & $0.00315\left(R_{e}^{\prime}>0.5+K^{\prime} / 16\right)^{\mathrm{a}}$
\end{tabular}

${ }^{\mathrm{a}}$ The original value 0.55 was modified to $0.5+K^{\prime} / 16$ based on the Dell and Bray model.

Table 2 Empirical potential parameters newly fitted for Al-O, Al-Al, Al-Na, Al-Si and Al-B pairs, as well as the parameters for $\mathrm{Si}-\mathrm{O}, \mathrm{Na}-\mathrm{O}, \mathrm{O}-\mathrm{O}, \mathrm{Si}-\mathrm{Si}, \mathrm{Si}-\mathrm{B}, \mathrm{B}-\mathrm{B}, \mathrm{B}-\mathrm{O}$ pairs from Kieu et al. ${ }^{24}$

\begin{tabular}{|c|c|c|c|}
\hline Pair & $A_{i j}(e V)$ & $\rho_{i j}(\AA)$ & $C_{i j}\left(e V \cdot \AA^{6}\right)$ \\
\hline Al-O & 28287.00 & 0.172 & 34.7600 \\
\hline $\mathrm{Al}-\mathrm{Al}$ & 351.94 & 0.360 & 0.0000 \\
\hline $\mathrm{Al}-\mathrm{Na}$ & 175.21 & 0.130 & 0.0000 \\
\hline $\mathrm{Al}-\mathrm{Si}$ & 646.67 & 0.120 & 0.0000 \\
\hline Al-B & 137.58 & 0.479 & 0.0000 \\
\hline $\mathrm{Si}-\mathrm{O}^{\mathrm{a}}$ & 45296.72 & 0.161 & 46.1395 \\
\hline $\mathrm{Na}-\mathrm{O}^{\mathrm{a}}$ & 120360.22 & 0.170 & 0.0000 \\
\hline $\mathrm{O}-\mathrm{O}^{\mathrm{a}}$ & 9027.03 & 0.265 & 85.0321 \\
\hline $\mathrm{Si}-\mathrm{Si}^{\mathrm{a}}$ & 834.40 & 0.290 & 0.0000 \\
\hline $\mathrm{Si}-\mathrm{B}^{\mathrm{a}}$ & 337.70 & 0.290 & 0.0000 \\
\hline$B-B^{a}$ & 121.10 & 0.350 & 0.0000 \\
\hline $\mathrm{B}-\mathrm{O}^{\mathrm{a}, \mathrm{b}}$ & $\mathrm{A}_{\mathrm{B}-\mathrm{O}}(\text { from Eq. } 4)^{\mathrm{a}}$ & $0.124^{\mathrm{b}}$ & $35.0019^{\mathrm{b}}$ \\
\hline
\end{tabular}

\footnotetext{
${ }^{\mathrm{a}}$ Pair parameters are from Kieu et $\mathrm{al}^{24}$.

${ }^{\mathrm{b}}$ Updated B-O parameters from Kwon et $\mathrm{al}^{32}$.
} 


\subsubsection{Parameters for $\mathrm{Al}$ related pairs}

The Al related potential parameters were initially fitted to the experimental structure information of various crystals by using GULP ${ }^{33}$. The parameters were refined by systematically adjusting the parameters to reproduce boron coordination and B-O bond distances in a series of sodium boroaluminosilicate glasses. This process involved simulations of large number of glass structures generated through the melt-and-quench process by using MD simulations. A weighted cost function was used to search for the optimal parameters. The final parameters for the sodium boroaluminosilicate glasses are shown in Table 2.

\subsubsection{Simulation procedures for glass generation}

The initial configurations with around 3000 atoms are randomly generated and overlapping atoms are pushed away from each other. These systems are first energy minimized at $0 \mathrm{~K}$ and then relaxed at $300 \mathrm{~K}$ for $60 \mathrm{ps}$. After the relaxation, these systems are melted at $6000 \mathrm{~K}$ for $60 \mathrm{ps}$, relaxed at $5000 \mathrm{~K}$ for $100 \mathrm{ps}$, and then cooled down to $300 \mathrm{~K}$ at a cooling rate of $5 \mathrm{~K} / \mathrm{ps}$. NPT ensemble relaxation is applied in order to obtain density information. All the final structures are relaxed using NVT and NVE ensembles in order to remove inner stress. The whole melting-

quench process is carried by DL_POLY simulation package ${ }^{34}$. This process is shown in Figure 1. 


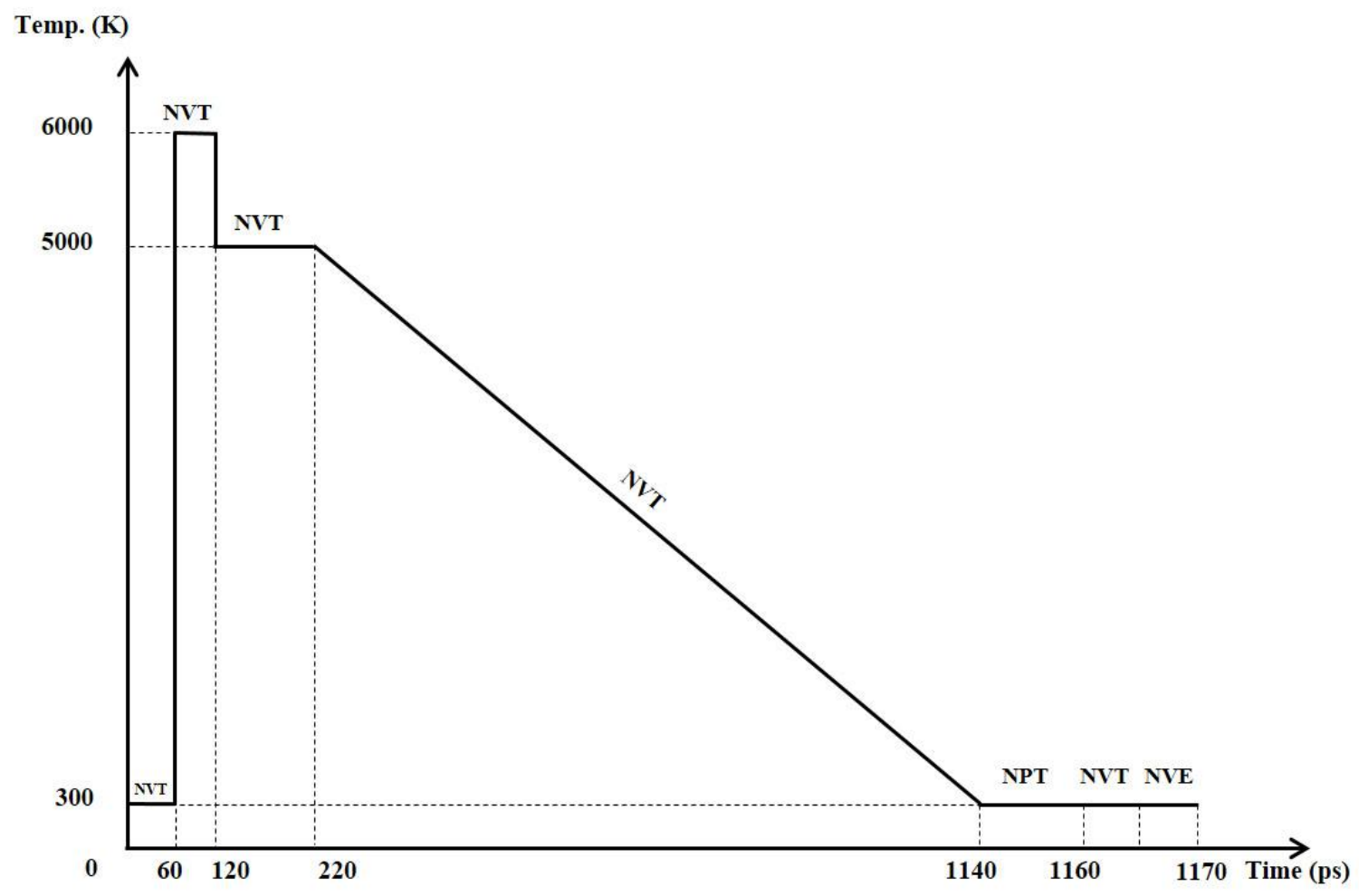

Figure 1 Temperature profile of the MD simulation process of glass formation.

\subsection{Structural analysis methods}

Various structure analysis methods have been used to study both short-range and intermediate-range order structural information. The typical analysis for the short-range structure of glass are pair distributions functions (PDF), bond angle distribution functions (BAD) and coordination number analysis. As long-range order structure units don't exist in amorphous materials due to the non-periodicity, the intermediate-range structural order is another important

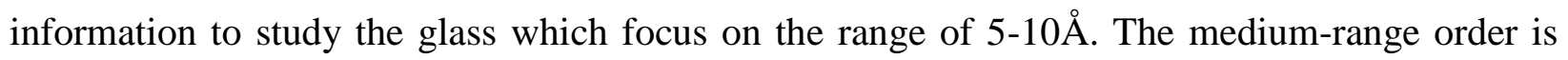
usually characterized by using $Q_{n}$ distribution and ring size distribution analysis.

\subsubsection{Pair distributions functions}

The PDF is basically the probability to find an atom at certain distance from the center atom. And the first peak gives the distance between two nearest atoms; therefore, the center position of the peak is considered as the bond distance of these two elements. The distributions of the 
interatomic distances of certain particle pairs in a given volume can be described through following equation:

$g(r)=\frac{1}{4 \pi r^{2} \rho \delta r} \frac{\sum_{t=1}^{T} \sum_{j=1}^{N} \Delta N(r \rightarrow r+\delta r)}{N \times T}$

where, $g(r)$ is the ratio between the local density and the bulk density of the system, $\rho$ is the number density of the system, $\mathrm{N}$ is the total number of the atoms, and $\mathrm{T}$ is the total time-step of the calculation, $\delta r$ is the integration step, and $\Delta \mathrm{N}$ is the number of atoms in the region between $\mathrm{r}$ and $\mathrm{r}+\delta r$. The structure factor of the system can be developed directly from $\mathrm{g}(\mathrm{r})$ through a Fourier transform; therefore, the PDF plot can be compared with the experimental data obtained from the X-ray or neutron diffraction ${ }^{35,36}$.

\subsubsection{Bond Angle Distribution}

BAD is a method to analyze the distribution of the angle formed by an atom together with two nearby atoms. The formula to calculate BAD is shown by following equation ${ }^{37}$ :

$a_{i j k}(\theta)=\frac{1}{N_{a}} \sum_{l=1}^{N_{a}} \delta\left(\theta-\left(\theta_{i j k}\right)_{l}\right)$

Where, $\theta_{i j k}$ is the angle formed by atom $j$ and two closest atoms $i$ and $k . N_{a}$ is the number of all angles formed by atoms $i, j$ (center atom) and $k$. The cutoff value is the first minimum point after the first intense peak on the pair distribution function plot. The cutoff values we chose for the $\mathrm{Si}$ O, B-O and Al-O pairs are 2.25 $1.85 \AA$ and $2.25 \AA$, respectively.

\subsubsection{Coordination Number}

Coordination number $(\mathrm{CN})$ is the number of first nearest neighbor of the center atom $\mathrm{i}$ which can be obtained through counting the atom number of type $\mathrm{j}$ within the sphere of radium $r_{0}$. The $r_{0}$ value is the cutoff distance and is the same to the one in BAD calculation.

\subsection{4. $Q_{n}$ Distribution and Ring Size Distribution}

$\mathrm{Q}_{\mathrm{n}}$ distribution is a method to count the number of each $\mathrm{Q}_{\mathrm{n}}$ species which is originally defined in a "quaternary" (four-coordinated) units. The $\mathrm{Q}_{\mathrm{n}}$ is formed by the glass network former atom and the nearest neighbor oxygen atoms, while " $n$ " stands for the number of surrounding bridging oxygen atoms connected to each center glass-former atom. However, for Al and B polyhedrons, there exist "trinary" (three-coordinated) or "quinary" (five-coordinated) units. In this paper, we use $\mathrm{Q}_{\mathrm{n}}$ for all these three polyhedral units in the multicomponent glass systems, although other coordinated units may exist. 
Another way to describe the intermediate-range structure is the ring size distribution analysis which gives the information of the glass network connectivity. Number of polyhedrons forming smallest ring is counted and the bridging oxygen is not taken into consideration.

\subsection{Property calculations}

\subsubsection{Vibrational properties measurement}

The total and partial vibrational density of states (VDOS) is a way to study the vibrational properties of glass systems ${ }^{38}$. To obtain the VDOS data, Fourier transformation is applied to velocity autocorrelation function through following equation:

$\mathrm{g}(\omega)=\frac{2}{\pi} \int_{0}^{\infty} C(t) \cos (\omega t) d t$

where, $\omega$ is the frequency of vibration, $\mathrm{C}(\mathrm{t})$ is the velocity autocorrelation function, and $\mathrm{t}$ is the time. Partial VDOS is noted as $g_{\alpha}(\omega)$, where $\alpha$ is $\mathrm{Al}, \mathrm{B}, \mathrm{Na}, \mathrm{Si}, \mathrm{O},{ }^{[3]} \mathrm{B}$ and ${ }^{[4]} \mathrm{B}$.

\subsubsection{Mechanical properties measurement}

As a way to describe the stiffness of a material, the elastic constant matrix can be obtained by solving the relationship between stress and strain tensors through a deformation process. The notation can be expressed as:

$$
S_{i j}=C_{i j k l} * \epsilon_{k l}
$$

Where, $S_{i j}$ are symmetric stress tensor elements, $C_{i j k l}$ are the fourth rank of the elastic constants, and $\epsilon_{k l}$ are the symmetric strain elements. The number of distinct constants reduced by symmetry is 21 . Deformations of the stimulated configurations are applied from six directions (x, $y, z, x y, y z, x z)$, and zero energy minimization method are employed to obtain the elastic constant matrix. The calculations were carried by using the LAMMPS ${ }^{39}$ package. Elastic moduli are calculated using Hill's methods ${ }^{40}$, in which the geometric average values of the Voigt and Reuss ones are used. The Voigt and Reuss bulk modulus values can be obtained through the Equations 18 and 19:

$$
\begin{aligned}
& B_{R}=1 /\left(S_{11}+S_{22}+S_{33}+2 \times\left(S_{31}+S_{21}+S_{32}\right)\right) \\
& B_{V}=\frac{1}{9} \times\left(C_{11}+C_{22}+C_{33}+2 \times\left(C_{12}+C_{13}+C_{23}\right)\right.
\end{aligned}
$$

And the shear modulus ones are calculated by the following equations:

$$
\begin{aligned}
& G_{R}=15 /\left(4 \times\left(S_{11}+S_{22}+S_{33}\right)-4 \times\left(S_{12}+S_{23}+S_{31}\right)+3 \times\left(S_{44}+S_{55}+S_{66}\right)\right) \\
& G_{V}=\frac{1}{15} \times\left(\left(C_{11}+C_{22}+C_{33}\right)-\left(C_{12}+C_{23}+C_{31}\right)+3 \times\left(C_{44}+C_{55}+C_{66}\right)\right)
\end{aligned}
$$


The Young's modulus values were calculated based on the relationship between bulk modulus and shear modulus through Equation 22:

$E=\left(\frac{1}{3 \times G}+\frac{1}{9 \times K}\right)^{-1}$

Six glasses from randomly generated initial structures were generated and used for the mechanical property calculations and structure analysis. Average values of the properties and standard deviations were obtained from these samples of each composition.

\section{Results}

\subsection{Validation of the potential model and glass compositions for MD simulations}

To validate the newly developed aluminum related parameters, two aluminum containing ternary crystal structures were calculated using the developed potentials and compared with experimental structure values (Table 3). The new potential parameters were able to reproduce both structure features such as bond lengths, the unit cell volume and densities of these crystals.

By using the developed potentials, a series of glass compositions of sodium boroaluminosilicate glasses have been studied in this work. These glasses have the same constant amount of sodium oxide but varying concentrations of the three glass formers with formula being $16 \mathrm{Na}_{2} \mathrm{O}-4 \mathrm{xAl}_{2} \mathrm{O}_{3}-4 \mathrm{yB}_{2} \mathrm{O}_{3}-4(21-\mathrm{x}-\mathrm{y}) \mathrm{SiO}_{2}(\mathrm{x}=1,2,3,4$ and $\mathrm{y}=3,4,5,6)$. These compositions (abbreviated as SBNA x-y glasses) are summarized in Table 4 and the atomic charges of the simulated glass compositions can be found in the Appendix (Table 1). This series of glass covers wide range of $\mathrm{R}_{e}^{*}$ : from 0.00 to 0.688 ; therefore, the applicability of the newly developed potential has been tested.

Table 3 Structural information of $\mathrm{NaAlSiO}_{4}$ and $\mathrm{Na}_{2} \mathrm{Al}_{2} \mathrm{~B}_{2} \mathrm{O}_{7}$ crystal structures.

\begin{tabular}{|c|c|c|c|c|}
\hline \multirow{2}{*}{$\begin{array}{l}\text { Crystals } \\
\text { Source }\end{array}$} & \multicolumn{2}{|c|}{$\mathrm{NaAlSiO}_{4}$} & \multicolumn{2}{|c|}{$\mathrm{Na}_{2} \mathrm{Al}_{2} \mathrm{~B}_{2} \mathrm{O}_{7}$} \\
\hline & Experiment $^{4 \mathrm{I}}$ & Simulation & Experiment $^{42}$ & Simulation \\
\hline $\mathrm{a}(\AA)$ & 9.995 & 9.892 & 4.811 & 5.097 \\
\hline$b(\AA)$ & 9.995 & 9.892 & 4.811 & 5.097 \\
\hline$c(\AA)$ & 24.797 & 25.081 & 15.278 & 15.128 \\
\hline$\alpha\left({ }^{\circ}\right)$ & 90.0 & 90.0 & 90.0 & 90.0 \\
\hline$\beta\left(^{\circ}\right)$ & 90.0 & 90.0 & 90.0 & 90.0 \\
\hline$\gamma\left({ }^{\circ}\right)$ & 120.0 & 120.0 & 120.0 & 120.0 \\
\hline
\end{tabular}




\begin{tabular}{lcccc}
\hline $\mathrm{d}_{\text {Si-O }}(\AA)$ & 1.618 & 1.601 & - & - \\
$\mathrm{d}_{\mathrm{Al}-\mathrm{O}}(\AA)$ & 1.741 & 1.735 & 1.693 & 1.746 \\
$\mathrm{~d}_{\mathrm{Na}-\mathrm{O}}(\AA)$ & 2.562 & 2.651 & 2.668 & 2.761 \\
$\mathrm{~d}_{\mathrm{B}-\mathrm{O}}(\AA)$ & - & - & 1.408 & 1.362 \\
$\rho\left(\mathrm{g} / \mathrm{cm}^{3}\right)$ & 2.639 & 2.663 & 2.532 & 2.279 \\
\hline
\end{tabular}

Snapshot of the simulated structures of SBNA 1-6 and SBNA 4-6 are shown in Figure 2 a and $b$, respectively. The structures are shown in ball-stick (atom and bonding) style (Figure 2 a and b, upper) and can be seen that the glass structures are made of silicon-oxygen tetrahedrons, aluminum-oxygen tetrahedrons, and boron-oxygen triangles and tetrahedrons, which is shown in the polyhedron representation (Figure $2 \mathrm{a}$ and $\mathrm{b}$, lower). With composition change, the percentage of these network building blocks and their connectivity changes, which will be further analyzed in the subsequent sections.

Structure information such as coordination number, $Q_{n}$ species distributions, pair distribution functions and bond angle distribution functions of the simulated glasses have been analyzed. Additionally, medium range structures such as polyhedral connections and ring size distribution functions were also analyzed. Furthermore, the vibrational properties and mechanical properties of this series of glasses have been calculated and compared with previous simulation results and experimental data.

Table 4 Composition information of SBNA x-y glasses $\left(16 \mathrm{Na}_{2} \mathrm{O}-4 \mathrm{xAl}_{2} \mathrm{O}_{3}-4 \mathrm{yB}_{2} \mathrm{O}_{3}-4(21-\mathrm{x}-\mathrm{y})\right.$ $\mathrm{SiO}_{2}(\mathrm{x}=1,2,3,4$ and $\mathrm{y}=3,4,5,6){ }^{43}$ with calculated $\mathrm{N}_{4}^{\prime}$ and $\mathrm{R}_{e}^{*}$ values using our modified potential model.

\begin{tabular}{ccccccccccc}
\hline $\begin{array}{c}\text { SBNA x-y (in } \\
\text { mol \%) }\end{array}$ & $\mathrm{Na}_{2} \mathrm{O}$ & $\mathrm{Al}_{2} \mathrm{O}_{3}$ & $\mathrm{~B}_{2} \mathrm{O}_{3}$ & $\mathrm{SiO}_{2}$ & $\rho\left(\mathrm{g} / \mathrm{cm}^{3}\right)$ & $\boldsymbol{R}_{\boldsymbol{e}}$ & $\boldsymbol{K}_{\boldsymbol{e}}$ & $\boldsymbol{H}_{\boldsymbol{e}}$ & $\boldsymbol{N}_{\boldsymbol{4}}^{\prime \text { a) }}$ & $\mathbf{R}_{\boldsymbol{e}}^{* \text { b) }}$ \\
\hline SBNA 4-6 & 16 & 16 & 24 & 44 & 2.322 & 0.400 & 1.100 & 0.400 & 0.400 & 0.000 \\
SBNA 3-6 & 16 & 12 & 24 & 48 & 2.342 & 0.444 & 1.333 & 0.333 & 0.444 & 0.167 \\
SBNA 3-5 & 16 & 12 & 20 & 52 & 2.361 & 0.500 & 1.625 & 0.375 & 0.500 & 0.200 \\
SBNA 3-4 & 16 & 12 & 16 & 56 & 2.395 & 0.571 & 2.000 & 0.429 & 0.571 & 0.250 \\
SBNA 3-3 & 16 & 12 & 12 & 60 & 2.399 & 0.667 & 2.500 & 0.500 & 0.656 & 0.313 \\
SBNA 2-6 & 16 & 8 & 24 & 52 & 2.375 & 0.500 & 1.625 & 0.250 & 0.500 & 0.333 \\
\hline
\end{tabular}




\begin{tabular}{lllllllllll}
\hline SBNA 2-5 & 16 & 8 & 20 & 56 & 2.399 & 0.571 & 2.000 & 0.286 & 0.571 & 0.400 \\
SBNA 2-4 & 16 & 8 & 16 & 60 & 2.429 & 0.667 & 2.500 & 0.333 & 0.656 & 0.484 \\
SBNA 2-3 & 16 & 8 & 12 & 64 & 2.426 & 0.800 & 3.200 & 0.400 & 0.700 & 0.500 \\
SBNA 1-6 & 16 & 4 & 24 & 56 & 2.419 & 0.571 & 2.000 & 0.143 & 0.571 & 0.500 \\
SBNA 1-5 & 16 & 4 & 20 & 60 & 2.446 & 0.667 & 2.500 & 0.167 & 0.656 & 0.588 \\
SBNA 1-4 & 16 & 4 & 16 & 64 & 2.471 & 0.800 & 3.200 & 0.200 & 0.700 & 0.625 \\
SBNA 1-3 & 16 & 4 & 12 & 68 & 2.465 & 1.000 & 4.250 & 0.250 & 0.766 & 0.688 \\
\hline
\end{tabular}

a) The $N_{4}^{\prime}$ value is the theoretical percentage of four-coordinated boron and aluminum calculated by using Du and Stebbins's model ${ }^{8}$.

b) The $\mathrm{R}_{e}^{*}$ value calculated from equation 10 , and is equal to the $\mathrm{N}_{4}$ value in sodium boroaluminosilicate glasses based on Du and Stebbins's model ${ }^{8}$.
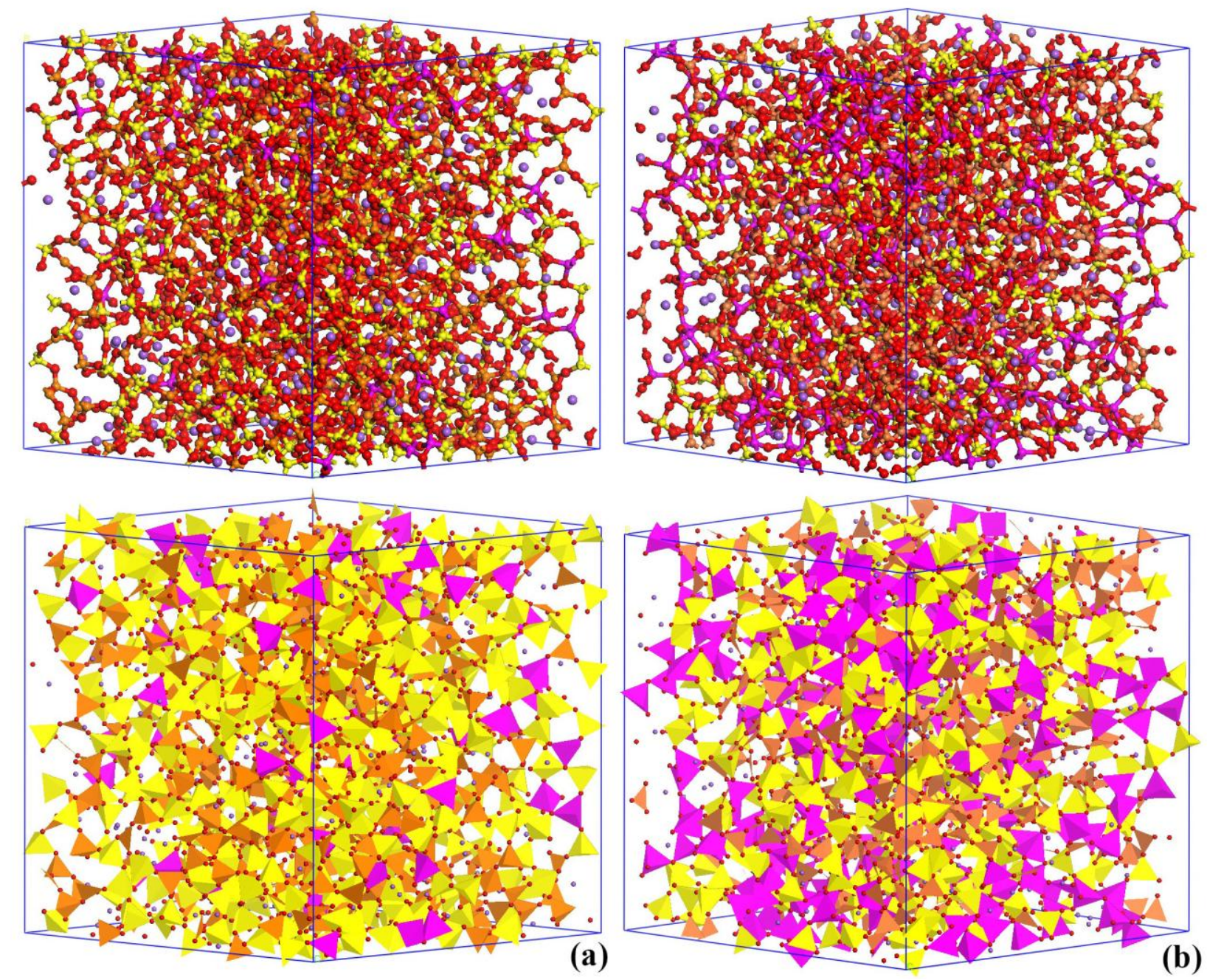
Figure 2 Simulated structures in ball-stick (top) and polyhedron (bottom) styles for a) SBNA 1-6 and b) SBNA 4-6, respectively. Red balls are oxygen atoms and purple balls are sodium atoms. Magenta, yellow and orange polyhedrons are for Al, Si and B, respectively.

\subsection{Short range structures}

\subsubsection{Pair distribution function analysis}

In order to give an inside view of the structures, one common used distribution function, the total distribution function has a form of $4 \pi \rho r g(r)$, has been studied. In order to keep it brief, the neutron broadened total distribution function and all the partial pair distributions are only plotted for the SBNA 3-3 glass as shown in Figure 3.

As shown in Figure 3, the first main peak of Si-O pair is located at around $1.61 \AA$ which is typical for silicon oxygen tetrahedrons. The Si-O bond distance of $1.61 \AA$ is in good agreement with previous MD simulation results for sodium aluminosilicate glasses ${ }^{7,44}$ and experimental value from X-ray absorption spectra for silicate glasses ${ }^{45}$.The first main peak of Al-O pair is centered at around $1.74 \AA$, which is in good agreement with previous MD simulation results for sodium aluminosilicate glasses ${ }^{7}$, as well as the experimental data collected by XRD and EXAFS for both alumina and sodium aluminosilicate glasses ${ }^{46-49}$. Detailed comparison between our simulated results and experimental data for main bond distances of the SBNA3-3 glass is listed in Table 5. In general, the simulation results are in good agreement with the experimental values. No diffraction data for any of the compositions studied in this work is available to further validate the potentials and this will be pursued in future work through collaboration with experimental groups. 


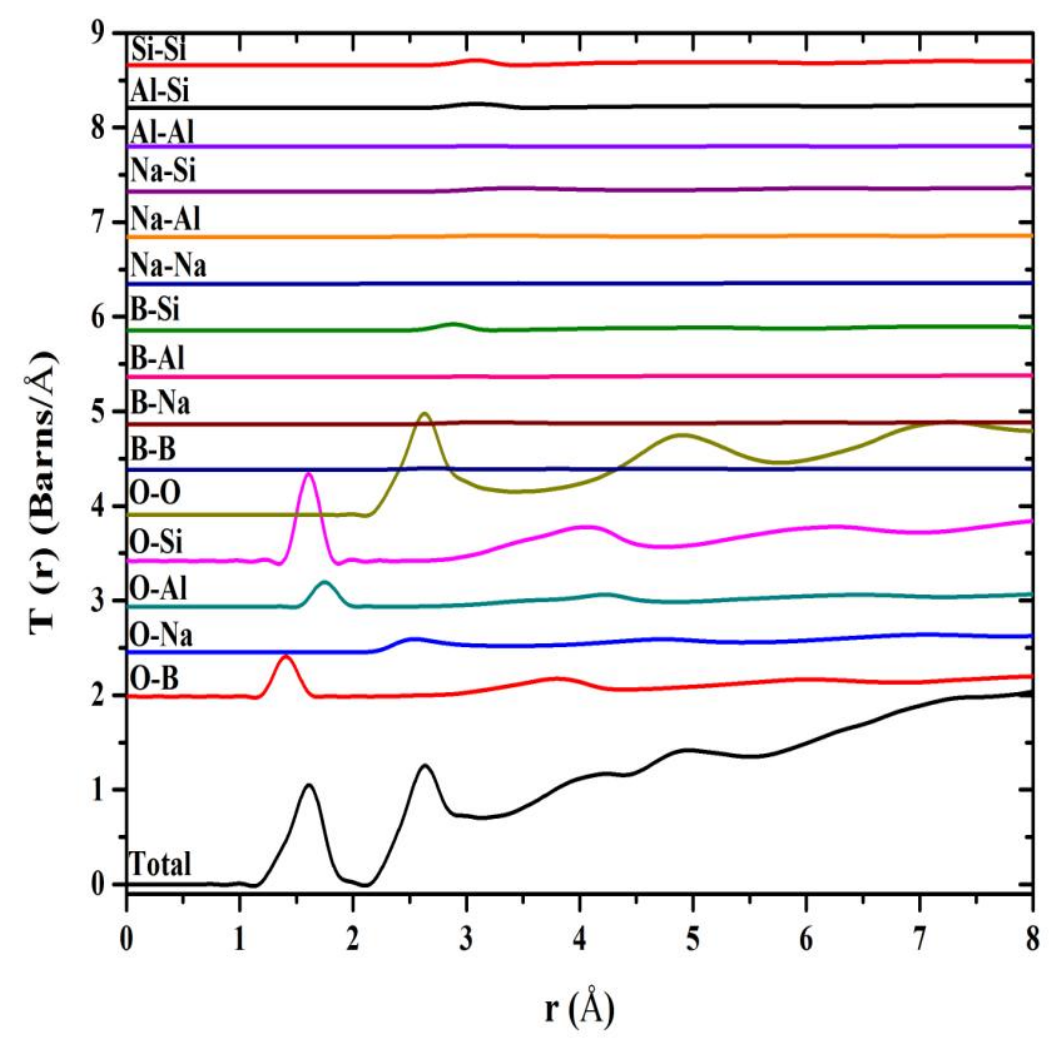

Figure 3 Simulated neutron broadened total correlation and partial pair distribution function for the SBNA 3-3 structure.

Table 5 Comparisons of bond distance of different pairs between experimental data and simulation results. The simulated bond distances are obtained from the SBNA3-3 glasses (16\% $\mathrm{Na}_{2} \mathrm{O}, 12 \% \mathrm{Al}_{2} \mathrm{O}_{3}, 12 \% \mathrm{~B}_{2} \mathrm{O}_{3}$ and $60 \% \mathrm{SiO}_{2}$ ).

\begin{tabular}{cccc}
\hline Bond length $(\AA)$ & This work & Previous simulation works & Experiment \\
\hline Si-O & 1.61 & $1.59-1.61^{44}$ & $1.60-1.61^{45}$ \\
Al-O & 1.74 & $1.74-1.75^{44}, 1.74^{7}, 1.78^{7}$ & $1.81^{46}, 1.83^{47}, 1.91^{48}, 1.77^{49}$ \\
Na-O & 2.51 & $2.4-2.6^{44}, 2.42^{7}, 2.46^{7}$ & $2.30-2.43^{45}, 2.46-2.62^{50}$ \\
\hline
\end{tabular}

The B-O pair distribution function plots (Figure 4 a) and b)) for two series of glasses have been obtained through equation 14. These two figures indicate that there are two main peaks in B-O PDF plot. For compositions with same alumina (Figure 4 a)), the first main peak locates at 
around $1.36 \AA$ for the SBNA 3-6 composition, and it shifts to the right to around $1.37 \AA$ for the SBNA 3-3 composition. The second main peak is centered at around 1.43 composition, and it shifts to higher $r$ values of $1.44 \AA$ for SBNA 3-3 composition. For those compositions with same boron oxide content (Figure 4 b)), the first main peak shifts from 1.36 for the SBNA 4-6 composition to $1.39 \AA$ for the SBNA 1-6 composition, and the second one shifts from 1.43 for the SBNA 4-6 composition to $1.45 \AA$ for the SBNA 1-6 composition. These two peaks are corresponding to three- and four-coordinated boron, respectively. The values of peak position are generally in good agreement with previous MD simulation results ${ }^{23,24}$ and $a b$ initio simulation results ${ }^{27}$ for $\mathrm{Na}-\mathrm{B}-\mathrm{Si}$ ternary systems, as well as the experimental data ${ }^{51}$ for vitreous boron oxide.
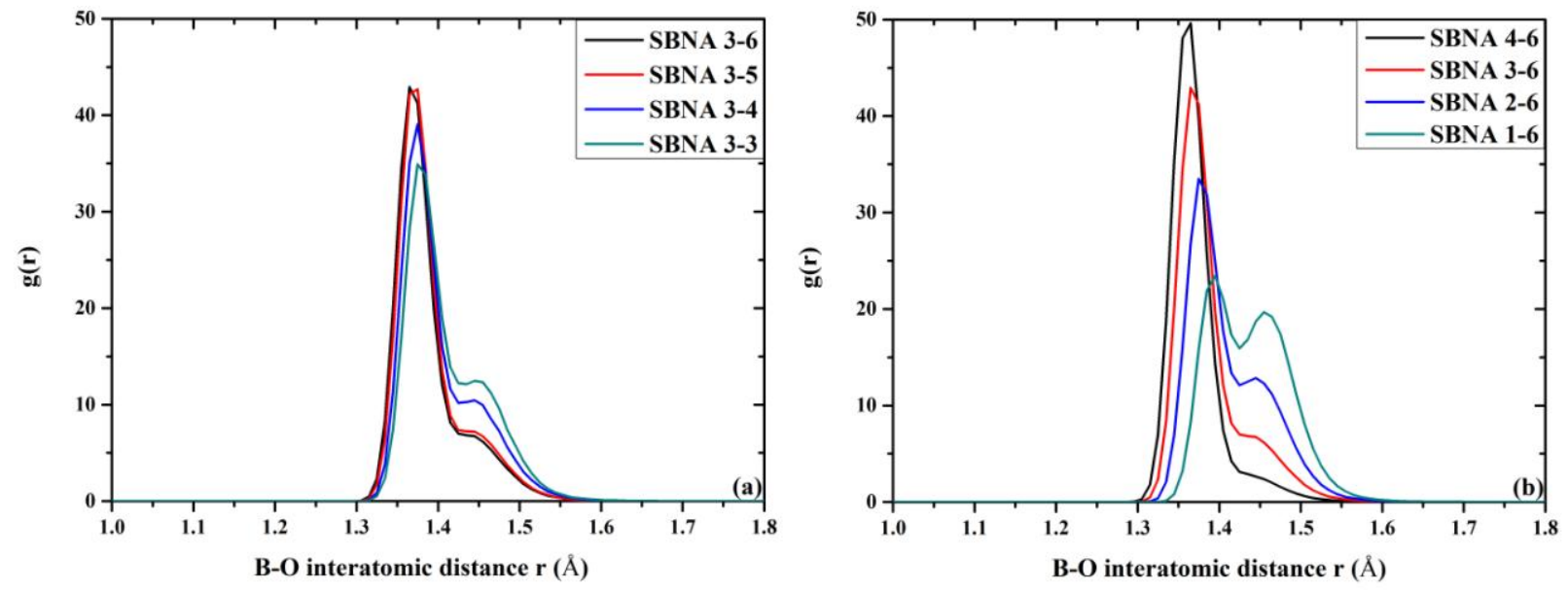

Figure 4 Comparison of the main peak positions in B-O PDF plots for compositions with a) same $\mathrm{Al}_{2} \mathrm{O}_{3}$ content and $\mathrm{b}$ ) same $\mathrm{B}_{2} \mathrm{O}_{3}$ content, respectively. The formula of these glasses is $16 \mathrm{Na}_{2} \mathrm{O}$ $4 \mathrm{xAl}_{2} \mathrm{O}_{3}-4 \mathrm{yB}_{2} \mathrm{O}_{3}-4(21-\mathrm{x}-\mathrm{y}) \mathrm{SiO}_{2}(\mathrm{x}=1,2,3,4$ and $\mathrm{y}=3,4,5,6)$

\subsubsection{Glass former cation coordination numbers $(\mathrm{CN})$}

The coordination number analysis of $\mathrm{Al}$ indicates that most of the aluminum ions are fourcoordinated and form $\left[\mathrm{AlO}_{4}\right]^{-}$tetrahedral units (Figure 5). This means most of the $\mathrm{Al}$ are converted from three/five coordinated to four coordinated, which is in good agreement with our presumption that modifier cation such as $\mathrm{Na}^{+}$first charge compensate $\left[\mathrm{AlO}_{4}\right]^{-}$units. The total percentage of the three and five coordinated aluminum is within $5 \%$. 


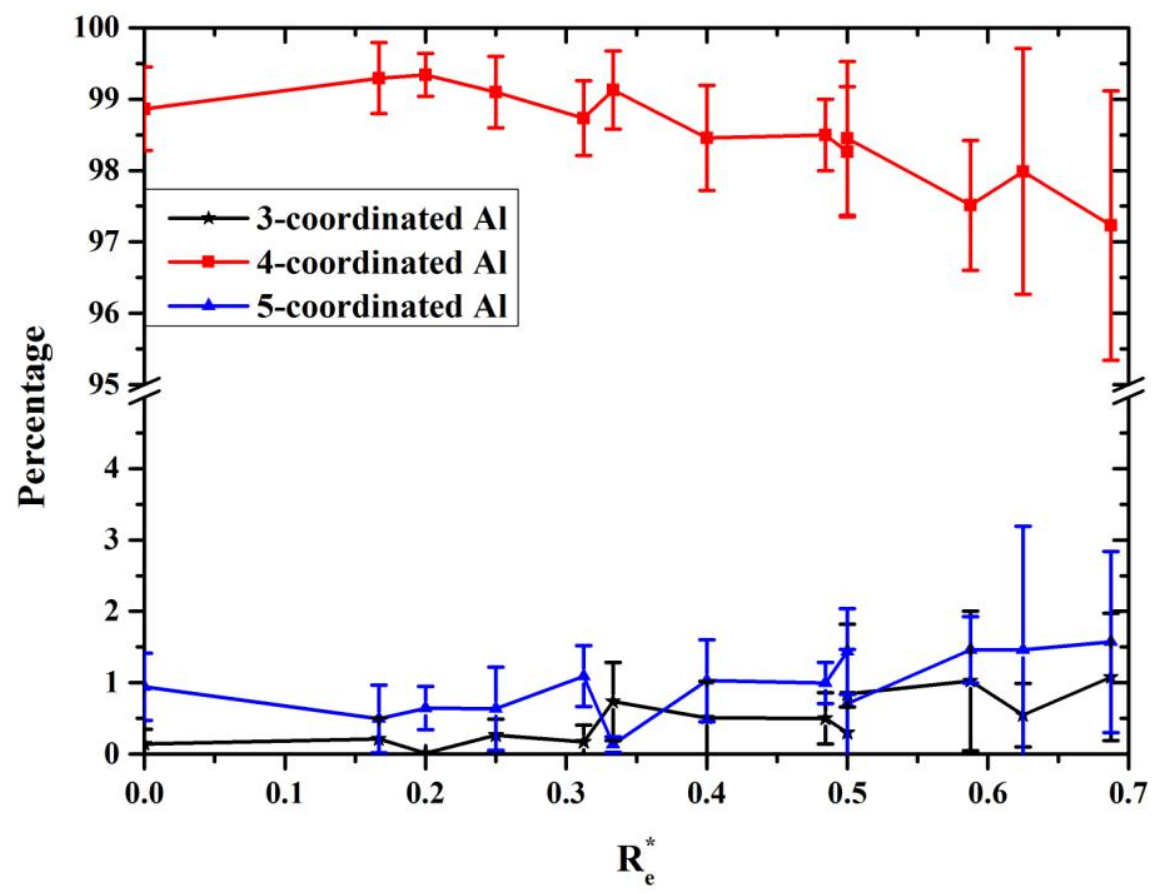

Figure 5 Percentage of 3 to 5 coordinated aluminum as a function of $R_{e}^{*}$ value. The $R_{e}^{*}$ value is calculated by solving equation 10 , and listed in Table 4 . The formula of these glasses is $16 \mathrm{Na}_{2} \mathrm{O}-$ $4 \mathrm{xAl}_{2} \mathrm{O}_{3}-4 \mathrm{yB}_{2} \mathrm{O}_{3}-4(21-\mathrm{x}-\mathrm{y}) \mathrm{SiO}_{2}(\mathrm{x}=1,2,3,4$ and $\mathrm{y}=3,4,5,6)$.

The Si coordination number is independent of $R_{e}^{*}$ value change and stays at 4.0 in all the compositions. This result validates the silicon part of this potential that most of Si atoms are four coordinated in these glasses and form the tetrahedral units.

The average number of four coordinated boron as a function of effective $\mathrm{R}$ value is shown in Figure 6. The values from simulations, together with those calculated from the Du and Stebbins for boroaluminosilicate glasses and the Yun, Dell and Bray model for borosilicate glasses, are compared in Figure 6. It can be seen that simulation results follow well of the trend of the Du and Stebbins model, with the overall difference between the theoretical value (calculated by the D\&B model and D\&S model) and simulated results being less than $10 \%$. We expected the presence of the irregular peak at $R_{e}^{*}=0.5$, since there are two sets of data points which stand for two compositions with different $R_{e}$ and $K_{e}$ values as shown in Table 4. Coincidentally, the $R_{e}^{*}$ values of these two compositions are calculated to be equal to each other by solving the equations 9 and 10. As a result, two sets of the data points can be found at $R_{e}^{*}=0.5$. 


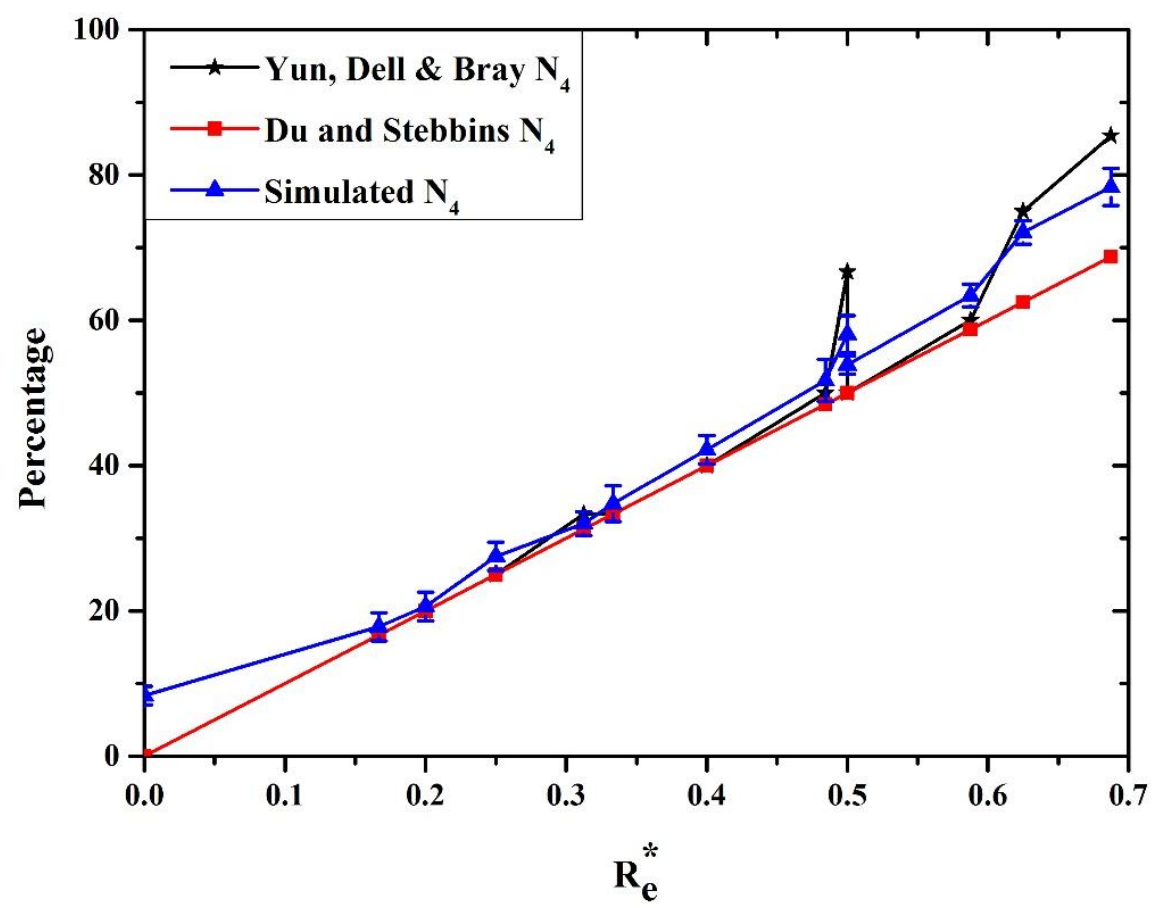

Figure 6 Percentage of four-coordinated B as a function of $R_{e}^{*}$ where $\mathrm{N}_{4}$ is four coordinated B. The simulation results (in blue triangles) are compared with the ones from YDB model (in black stars, using $\left.R_{e}^{*}=R^{\prime}=\left(\mathrm{Na}_{2} \mathrm{O}-\mathrm{Al}_{2} \mathrm{O}_{3}\right) / \mathrm{B}_{2} \mathrm{O}_{3}\right)$ and D\&S model (in red squares). The $\mathrm{R}_{e}^{*}$ value is calculated by solving equation 10 , and listed in Table 4 .

Further coordination analysis results are shown in Figure 7. It is shown that the simulated value $N_{4}^{\prime}$ (percentage of four coordinated $\mathrm{B}$ and $\mathrm{Al}$ ) follows the same trend of that calculated from the Du and Stebbins model. It is worth noting that the difference of $N_{4}^{\prime}$ between simulation and the model is larger for lower alumina content (small x value) (Figure $7 \mathrm{a}-\mathrm{c}$ )). And for the same amount of alumina, smaller y value or lower concentration of boron oxide also leads to larger differences of the $N_{4}^{\prime}$ values between simulation and the model. This is due to the presence of high $N_{4}$ differences of these compositions (shown in Figure $6, R_{e}^{*}$ from 0.5 to 0.67 ). The general good agreement shows that the Du and Stebbins model of B and Al coordination change is well reproduced by the new developed potential parameters; therefore, together with other agreement with experiments, the developed potentials enable MD simulations of sodium boroaluminosilicate glass systems. 

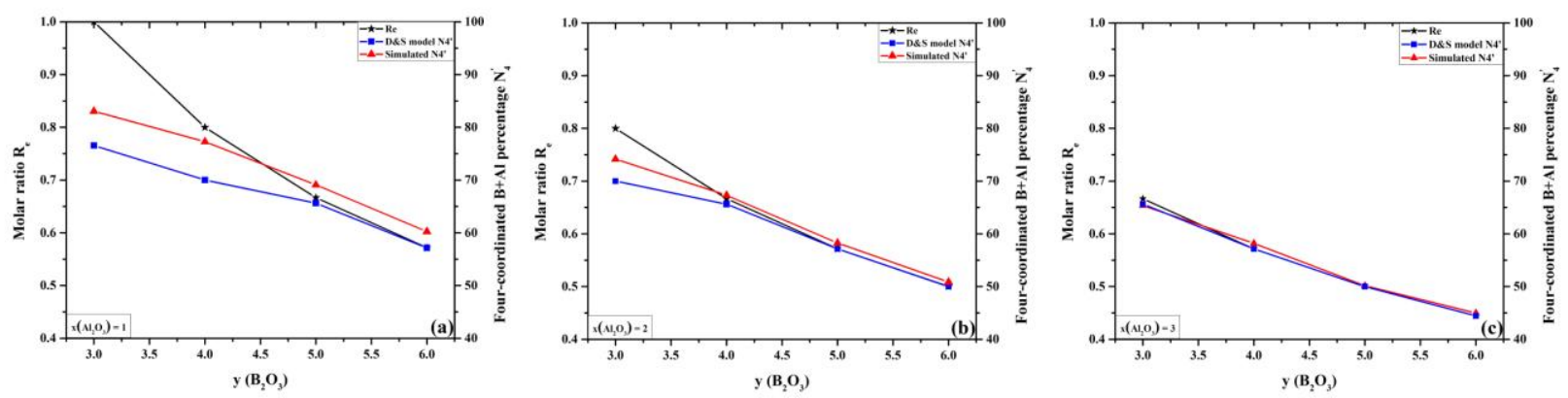

Figure 7 Molar ratio $\mathrm{R}_{e}\left(\mathrm{Na}_{2} \mathrm{O} /\left(\mathrm{B}_{2} \mathrm{O}_{3}+\mathrm{Al}_{2} \mathrm{O}_{3}\right)\right.$ ), theoretical $\mathrm{N}_{4}^{\prime}$ (fraction of four -fold coordinated boron, calculated by Du and Stebbin model) and simulated $N_{4}^{\prime}$ values as a function of $\mathrm{y}$ at different $\mathrm{x}$ value: $\mathrm{x}=1,2,3$ for a), b) and c), respectively. The $N_{4}^{\prime}$ value is the total fourcoordinated percentage of $\mathrm{B}$ and $\mathrm{Al}$. The formula of these glasses is $16 \mathrm{Na}_{2} \mathrm{O}-4 \mathrm{xAl}_{2} \mathrm{O}_{3}-4 \mathrm{yB}_{2} \mathrm{O}_{3}$ $4(21-x-y) \mathrm{SiO}_{2}(\mathrm{x}=1,2,3,4$ and $\mathrm{y}=3,4,5,6)$.

\subsection{1 $Q_{n}$ species distributions analysis}

The $\mathrm{Q}_{\mathrm{n}}$ (glass-former atoms connecting with $n$ bridging oxygen, as discussed in section 2) distribution provides information about how the network formers structural units connect with each other. Since $\mathrm{SiO}_{2}, \mathrm{~B}_{2} \mathrm{O}_{3}$ and $\mathrm{Al}_{2} \mathrm{O}_{3}$ are all considered as network formers, all the linkages connecting the structural units formed by these former cations are took into consideration. That is, the oxygen atoms in $\mathrm{Si}-\mathrm{O}-\mathrm{Al}, \mathrm{Si}-\mathrm{O}-\mathrm{B}$ and $\mathrm{B}-\mathrm{O}-\mathrm{Al}$ are also counted as a bridging oxygen.

$\mathrm{Q}_{\mathrm{n}}$ analysis of $\left[\mathrm{SiO}_{4}\right]$ and $\left[\mathrm{AlO}_{\mathrm{n}}\right]$ polyhedrons are shown in Table 6 and Table 7 , respectively. The results indicate that the preferred species for both $\mathrm{Si}$ and $\mathrm{Al}$ is $\mathrm{Q}_{4}$, suggesting high connectivity of network formers. For those compositions with same Al content, the number of $\mathrm{Q}_{4}$ specie increases while the B content is increasing; whereas, with same B content, this number increases while the $\mathrm{Al}$ content is decreasing. On the other hand, for those with same Si content, higher $\mathrm{Al}$ content gives lower $\mathrm{Q}_{4}$ species of the $\left[\mathrm{SiO}_{4}\right]$ units. Thus, additional B content increases the probability to form linkages between $\left[\mathrm{SiO}_{4}\right]$ and other glass-former polyhedral units; whereas, $\mathrm{Al}$ decreases this probability. Similar results can be found in the polyhedral analysis section shown later. Additionally, with the same amount of alumina (x), when boron oxide (y) gradually replacing silica, the percentage of silicon $\mathrm{Q}_{3}$ species decreases. In all compositions, $\mathrm{Q}_{2}$ species is close to zero.

Table 6. Percentage of $\mathrm{Q}_{\mathrm{n}}$ speciation of $\left[\mathrm{SiO}_{4}\right]$ units in SBNA x-y glasses $\left(16 \mathrm{Na}_{2} \mathrm{O}-4 \mathrm{xAl}_{2} \mathrm{O}_{3}\right.$ - 
$4 \mathrm{yB}_{2} \mathrm{O}_{3}-4(21-\mathrm{x}-\mathrm{y}) \mathrm{SiO}_{2}(\mathrm{x}=1,2,3,4$ and $\left.\mathrm{y}=3,4,5,6)\right)$ with the standard deviation from six parallel tests.

\begin{tabular}{ccccccc}
\hline Glass & $\mathrm{x}\left(\mathrm{Al}_{2} \mathrm{O}_{3}\right)$ & $\mathrm{y}\left(\mathrm{B}_{2} \mathrm{O}_{3}\right)$ & $(21-\mathrm{x}-\mathrm{y}) \mathrm{SiO}_{2}$ & $\mathrm{Q}_{2}$ & $\mathrm{Q}_{3}$ & $\mathrm{Q}_{4}$ \\
\hline SBNA 4-6 & 4 & 6 & 11 & $0.1 \pm 0.15$ & $4.6 \pm 0.69$ & $95.3 \pm 0.79$ \\
SBNA 3-6 & 3 & 6 & 12 & $0.0 \pm 0.10$ & $5.0 \pm 1.11$ & $95.0 \pm 1.17$ \\
SBNA 3-5 & 3 & 5 & 13 & $0.2 \pm 0.27$ & $6.2 \pm 1.09$ & $93.6 \pm 1.09$ \\
SBNA 3-4 & 3 & 4 & 14 & $0.2 \pm 0.27$ & $6.1 \pm 0.64$ & $93.7 \pm 0.87$ \\
SBNA 3-3 & 3 & 3 & 15 & $0.0 \pm 0.08$ & $7.0 \pm 0.47$ & $93.0 \pm 0.47$ \\
SBNA 2-6 & 2 & 6 & 13 & $0.0 \pm 0.10$ & $4.5 \pm 1.30$ & $95.5 \pm 1.26$ \\
SBNA 2-5 & 2 & 5 & 14 & $0.1 \pm 0.11$ & $4.8 \pm 0.98$ & $95.1 \pm 1.08$ \\
SBNA 2-4 & 2 & 4 & 15 & $0.1 \pm 0.15$ & $5.9 \pm 1.13$ & $94.0 \pm 1.18$ \\
SBNA 2-3 & 2 & 3 & 16 & $0.2 \pm 0.20$ & $7.9 \pm 0.52$ & $91.9 \pm 0.67$ \\
SBNA 1-6 & 1 & 6 & 14 & $0.1 \pm 0.11$ & $3.8 \pm 0.69$ & $96.1 \pm 0.62$ \\
SBNA 1-5 & 1 & 5 & 15 & $0.2 \pm 0.08$ & $4.9 \pm 0.33$ & $94.9 \pm 0.27$ \\
SBNA 1-4 & 1 & 4 & 16 & $0.0 \pm 0.07$ & $6.3 \pm 0.35$ & $93.7 \pm 0.34$ \\
SBNA 1-3 & 1 & 3 & 17 & $0.3 \pm 0.27$ & $10.6 \pm 0.70$ & $89.1 \pm 0.68$ \\
\hline
\end{tabular}

For $\left[\mathrm{AlO}_{\mathrm{n}}\right]$, there exists small amount of $\mathrm{Q}_{3}$ and $\mathrm{Q}_{5}$ with majority (over 95\%) being $\mathrm{Q}_{4}$. Increasing B content (at same $\mathrm{Al}$ content) generally increases the number of $\mathrm{Q}_{4}$ units. That is, the $\mathrm{B}$ content increases the probability of forming linkages between $\left[\mathrm{AlO}_{\mathrm{n}}\right]$ and other glass-former polyhedral units. The existence of $\mathrm{Q}_{5}$ units is caused by the presence of 5 coordinated $\mathrm{Al}$ in the glasses. It also suggests that most of aluminum ions are connected to the other network formers in the glass network.

Table 7. Percentage of $\mathrm{Q}_{\mathrm{n}}$ speciation of $\left[\mathrm{AlO}_{\mathrm{n}}\right]$ units in SBNA x-y glasses $\left(16 \mathrm{Na}_{2} \mathrm{O}-4 \mathrm{xAl}_{2} \mathrm{O}_{3}\right.$ $4 \mathrm{yB}_{2} \mathrm{O}_{3}-4(21-\mathrm{x}-\mathrm{y}) \mathrm{SiO}_{2}(\mathrm{x}=1,2,3,4$ and $\left.\mathrm{y}=3,4,5,6)\right)$ with the standard deviation from six parallel tests.

\begin{tabular}{ccccccc}
\hline Glass & $\mathrm{x}\left(\mathrm{Al}_{2} \mathrm{O}_{3}\right)$ & $\mathrm{y}\left(\mathrm{B}_{2} \mathrm{O}_{3}\right)$ & $(21-\mathrm{x}-\mathrm{y}) \mathrm{SiO}_{2}$ & $\mathrm{Q}_{3}$ & $\mathrm{Q}_{4}$ & $\mathrm{Q}_{5}$ \\
\hline SBNA 4-6 & 4 & 6 & 11 & $1.8 \pm 0.70$ & $97.2 \pm 0.76$ & $1.0 \pm 0.47$ \\
SBNA 3-6 & 3 & 6 & 12 & $2.0 \pm 0.73$ & $97.5 \pm 0.80$ & $0.5 \pm 0.48$ \\
SBNA 3-5 & 3 & 5 & 13 & $1.7 \pm 1.09$ & $97.7 \pm 1.06$ & $0.6 \pm 0.30$ \\
SBNA 3-4 & 3 & 4 & 14 & $2.2 \pm 0.65$ & $97.2 \pm 0.81$ & $0.6 \pm 0.58$ \\
SBNA 3-3 & 3 & 3 & 15 & $2.1 \pm 1.34$ & $96.8 \pm 1.63$ & $1.1 \pm 0.43$ \\
SBNA 2-6 & 2 & 6 & 13 & $1.9 \pm 1.13$ & $98.0 \pm 1.18$ & $0.1 \pm 0.11$ \\
SBNA 2-5 & 2 & 5 & 14 & $2.3 \pm 1.51$ & $96.7 \pm 1.84$ & $1.0 \pm 0.57$ \\
SBNA 2-4 & 2 & 4 & 15 & $1.2 \pm 0.98$ & $97.8 \pm 1.05$ & $1.0 \pm 0.29$ \\
SBNA 2-3 & 2 & 3 & 16 & $1.9 \pm 1.33$ & $96.7 \pm 1.65$ & $1.4 \pm 0.60$ \\
SBNA 1-6 & 1 & 6 & 14 & $1.6 \pm 1.28$ & $97.7 \pm 1.12$ & $0.7 \pm 0.76$ \\
SBNA 1-5 & 1 & 5 & 15 & $3.0 \pm 2.70$ & $95.5 \pm 2.41$ & $1.5 \pm 0.47$ \\
\hline
\end{tabular}




\begin{tabular}{lllllll}
\hline SBNA 1-4 & 1 & 4 & 16 & $2.7 \pm 1.22$ & $95.9 \pm 1.22$ & $1.4 \pm 1.73$ \\
SBNA 1-3 & 1 & 3 & 17 & $2.7 \pm 1.56$ & $95.7 \pm 2.75$ & $1.6 \pm 1.27$ \\
\hline
\end{tabular}

The $\mathrm{Q}_{\mathrm{n}}$ distribution of $\left[\mathrm{BO}_{3}\right]$ and $\left[\mathrm{BO}_{4}\right]$ units is shown in Table 8 . The main species are $\mathrm{Q}_{3}$ and $\mathrm{Q}_{4}$ for $\left[\mathrm{BO}_{3}\right]$ and $\left[\mathrm{BO}_{4}\right]$ units, respectively. And the $\mathrm{Q}_{1}$ and $\mathrm{Q}_{2}$ species in $\left[\mathrm{BO}_{3}\right]$ units and $\mathrm{Q}_{3}$ species in $\left[\mathrm{BO}_{4}\right]$ units are due to the association of non-bridging oxygen with boron polyhedral units. With the same soda and silica content (same $\mathrm{x}+\mathrm{y}$ value), increasing B/Al ratio (x/y) leads to an increase of the amount of $\mathrm{Q}_{3}$ specie of the three-coordinated boron, and the amount of $\mathrm{Q}_{4}$ species of $\left[\mathrm{BO}_{4}\right]$ units gives similar trend.

Table 8. Percentage of $\mathrm{Q}_{\mathrm{n}}$ speciation of $\left[\mathrm{BO}_{3}\right]$ and $\left[\mathrm{BO}_{4}\right]$ units in SBNA x-y glasses $\left(16 \mathrm{Na}_{2} \mathrm{O}-\right.$ $4 \mathrm{xAl}_{2} \mathrm{O}_{3}-4 \mathrm{yB}_{2} \mathrm{O}_{3}-4(21-\mathrm{x}-\mathrm{y}) \mathrm{SiO}_{2}(\mathrm{x}=1,2,3,4$ and $\left.\mathrm{y}=3,4,5,6)\right)$ with the standard deviation from six parallel tests.

\begin{tabular}{ccccccc}
\hline $\mathrm{Q}_{\mathrm{n}}$ of 3-coord. B & $\mathrm{n}=1$ & $\mathrm{n}=2$ & $\mathrm{n}=3$ & $\mathrm{Q}_{\mathrm{n}}$ of 4-coord. B & $\mathrm{n}=3$ & $\mathrm{n}=4$ \\
\hline SBNA 4-6 & $0.1 \pm 0.20$ & $7.2 \pm 1.61$ & $92.7 \pm 1.45$ & SBNA 4-6 & $1.5 \pm 2.48$ & $98.4 \pm 2.55$ \\
SBNA 3-6 & $0.1 \pm 0.13$ & $6.7 \pm 1.35$ & $93.2 \pm 1.45$ & SBNA 3-6 & $2.4 \pm 1.87$ & $97.4 \pm 1.66$ \\
SBNA 3-5 & $0.1 \pm 0.16$ & $7.4 \pm 1.39$ & $92.5 \pm 1.49$ & SBNA 3-5 & $1.0 \pm 1.17$ & $98.7 \pm 1.13$ \\
SBNA 3-4 & $0.1 \pm 0.21$ & $8.6 \pm 1.65$ & $91.3 \pm 1.79$ & SBNA 3-4 & $3.4 \pm 1.32$ & $96.6 \pm 1.32$ \\
SBNA 3-3 & $0.2 \pm 0.37$ & $8.8 \pm 1.52$ & $91.0 \pm 1.81$ & SBNA 3-3 & $5.0 \pm 2.94$ & $95.0 \pm 2.94$ \\
SBNA 2-6 & $0.0 \pm 0.00$ & $5.4 \pm 1.34$ & $94.6 \pm 1.34$ & SBNA 2-6 & $0.9 \pm 1.01$ & $99.0 \pm 1.17$ \\
SBNA 2-5 & $0.2 \pm 0.26$ & $6.3 \pm 1.47$ & $93.5 \pm 1.49$ & SBNA 2-5 & $2.6 \pm 1.14$ & $97.4 \pm 1.13$ \\
SBNA 2-4 & $0.0 \pm 0.00$ & $6.1 \pm 2.43$ & $93.9 \pm 2.43$ & SBNA 2-4 & $1.7 \pm 1.76$ & $98.3 \pm 1.76$ \\
SBNA 2-3 & $0.0 \pm 0.00$ & $9.3 \pm 1.69$ & $90.7 \pm 1.69$ & SBNA 2-3 & $5.2 \pm 2.24$ & $94.6 \pm 2.39$ \\
SBNA 1-6 & $0.0 \pm 0.00$ & $3.6 \pm 0.66$ & $96.4 \pm 0.66$ & SBNA 1-6 & $1.8 \pm 1.03$ & $98.1 \pm 1.16$ \\
SBNA 1-5 & $0.0 \pm 0.00$ & $3.7 \pm 0.68$ & $96.3 \pm 0.68$ & SBNA 1-5 & $2.7 \pm 0.82$ & $97.3 \pm 0.82$ \\
SBNA 1-4 & $0.6 \pm 0.71$ & $5.7 \pm 1.98$ & $93.7 \pm 2.05$ & SBNA 1-4 & $4.1 \pm 1.11$ & $95.7 \pm 1.23$ \\
SBNA 1-3 & $0.0 \pm 0.00$ & $9.1 \pm 4.48$ & $90.9 \pm 4.48$ & SBNA 1-3 & $3.3 \pm 1.45$ & $96.6 \pm 1.47$ \\
\hline
\end{tabular}

With the same sodium and aluminum content (same $\mathrm{x}$ value), the increase of boron content (and decrease of silica content) results in an increase trend of the $\mathrm{Q}_{3}$ species of three-coordinated boron (in Figure $8 \mathrm{a}$ )) and $\mathrm{Q}_{4}$ species of four-coordinated boron (in Figure $8 \mathrm{~b}$ )). These are due to the availability of more sodium ions to combine with $\left[\mathrm{BO}_{3}\right]$ and $\left[\mathrm{BO}_{4}\right]$ units, and less competition of aluminum/silicon for sodium and oxygen. In addition, with same sodium and boron content (same y value), decreasing aluminum content (and increasing silicon content) slightly increases the $\mathrm{Q}_{3}$ species of three-coordinated boron, especially at high boron 
concentration ones. This indicates that silica has stronger network-forming ability than aluminum oxide in these glasses.
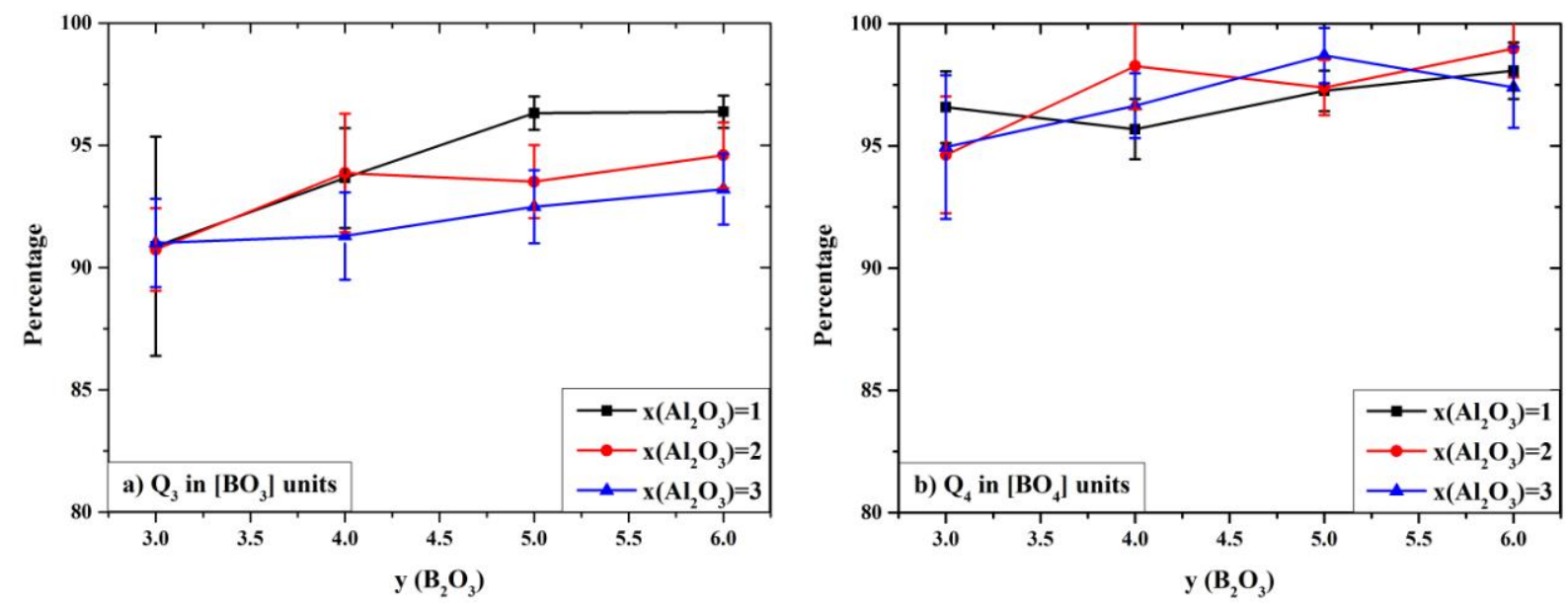

Figure 8 Main $\mathrm{Q}_{\mathrm{n}}$ species percentage vs boron concentration in a) $\left[\mathrm{BO}_{3}\right]$ and b) $\left[\mathrm{BO}_{4}\right]$ units at different $x\left(\mathrm{Al}_{2} \mathrm{O}_{3}\right.$ content $)$, respectively. The values in these plots are the averaged value of six parallel tests with the standard error bar, and the lines are the guide of eyes. The glass compositions are SBNA $x-y: 16 \mathrm{Na}_{2} \mathrm{O}-4 \mathrm{xAl}_{2} \mathrm{O}_{3}-4 \mathrm{yB}_{2} \mathrm{O}_{3}-4(21-\mathrm{x}-\mathrm{y}) \mathrm{SiO}_{2}(\mathrm{x}=1,2,3$ and $\mathrm{y}=3,4,5$, $6)$.

\subsubsection{Bond angle distribution analysis (BAD)}

The bond angle distributions have been analyzed for the angle inside a polyhedron, as well as the angle formed by two glass-former atoms in two different polyhedrons and an oxygen atom in the center (inter-polyhedron). Figure 9 a) shows the $\mathrm{O}-\mathrm{Si}-\mathrm{O}$ bond angle distribution and it indicates that the main peak of O-Si-O distribution is located at around 109.5 degree, which is close to the theoretical angle in a tetrahedral unit. The O-Al-O bond angle distribution gives a relatively broad peak, as compared to the main peak in $\mathrm{O}-\mathrm{Si}-\mathrm{O}$ distribution, and the main peak locates at around 107 degree. The results of $\mathrm{O}-\mathrm{Si}-\mathrm{O}$ and $\mathrm{O}-\mathrm{Al}-\mathrm{O}$ distributions are similar to previous simulation results in sodium aluminosilicate glasses ${ }^{7}$. The inter-polyhedron BAD as shown in Figure 9 b) gives general information about how the polyhedrons connect with each other, e.g., the bond angle formed by two polyhedrons and center oxygen atoms. The main peak of the Al-O-Al bond angle centered at around 120 degree, and is in good agreement with previous simulation results for sodium aluminosilicate glasses ${ }^{7}$. The intensity of the peak for 
each bond angle also reflects the forming probability of the linkage between two polyhedrons. For example, the higher Al-O-Si peak intensity indicates the Al-O-Si linkage is the most favorable one in this glass.
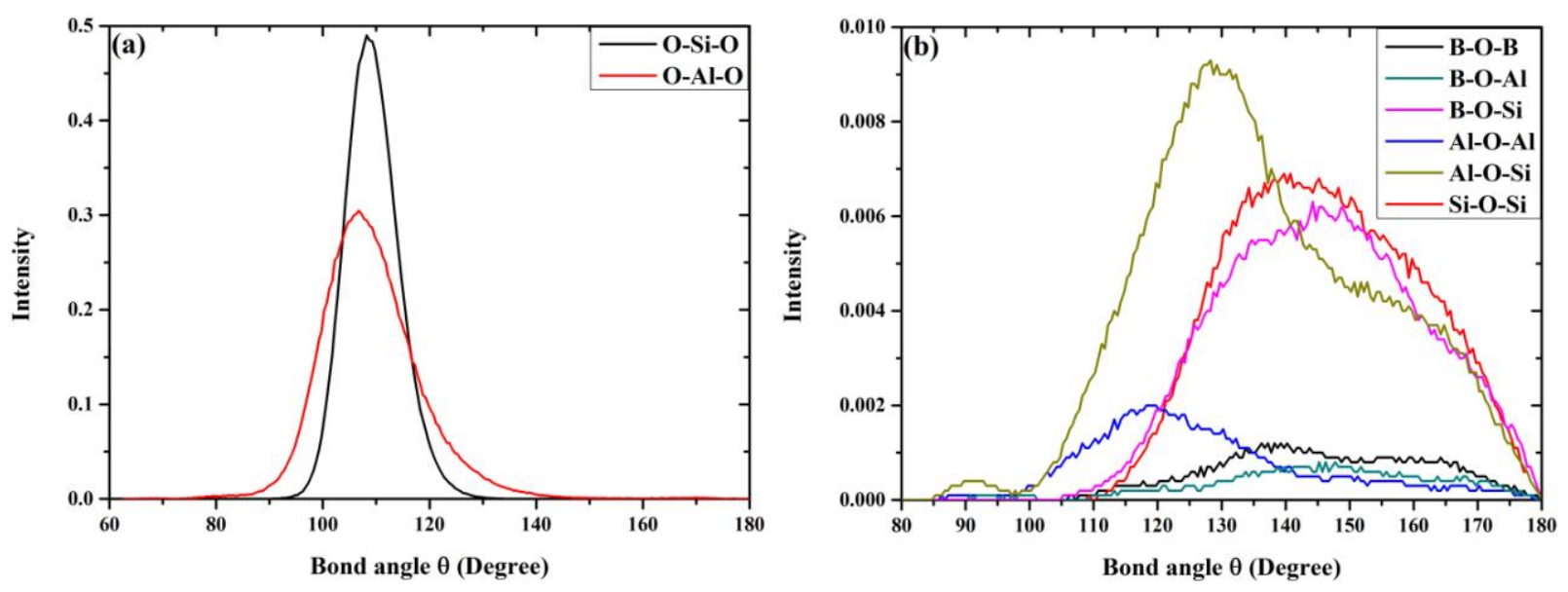

Figure 9 a) Bond angle distributions and b) inter-polyhedron bond angle distributions plots for SBNA 3-3 structure. The glass compositions are SBNA x-y: $16 \mathrm{Na}_{2} \mathrm{O}-4 \mathrm{xAl}_{2} \mathrm{O}_{3}-4 \mathrm{yB}_{2} \mathrm{O}_{3}-4(21-\mathrm{x}-\mathrm{y})$ $\mathrm{SiO}_{2}(\mathrm{x}=1,2,3$ and $\mathrm{y}=3,4,5,6)$.

The O-B-O bond angle distributions of two series of glass structures were analyzed and shown in Figure 10 a) and b). Two main peaks in the BAD plots of O-B-O are observed: the first peak locates at around 109.5 degree which corresponds to the four coordinated boron and the second peak is centered at around 120.0 degree which corresponds to the three coordinated boron. While compositions varying, the positions of these two peaks stay the same; whereas, the intensity of the peaks changes since the number of three and four-coordinated boron changes in those compositions. 

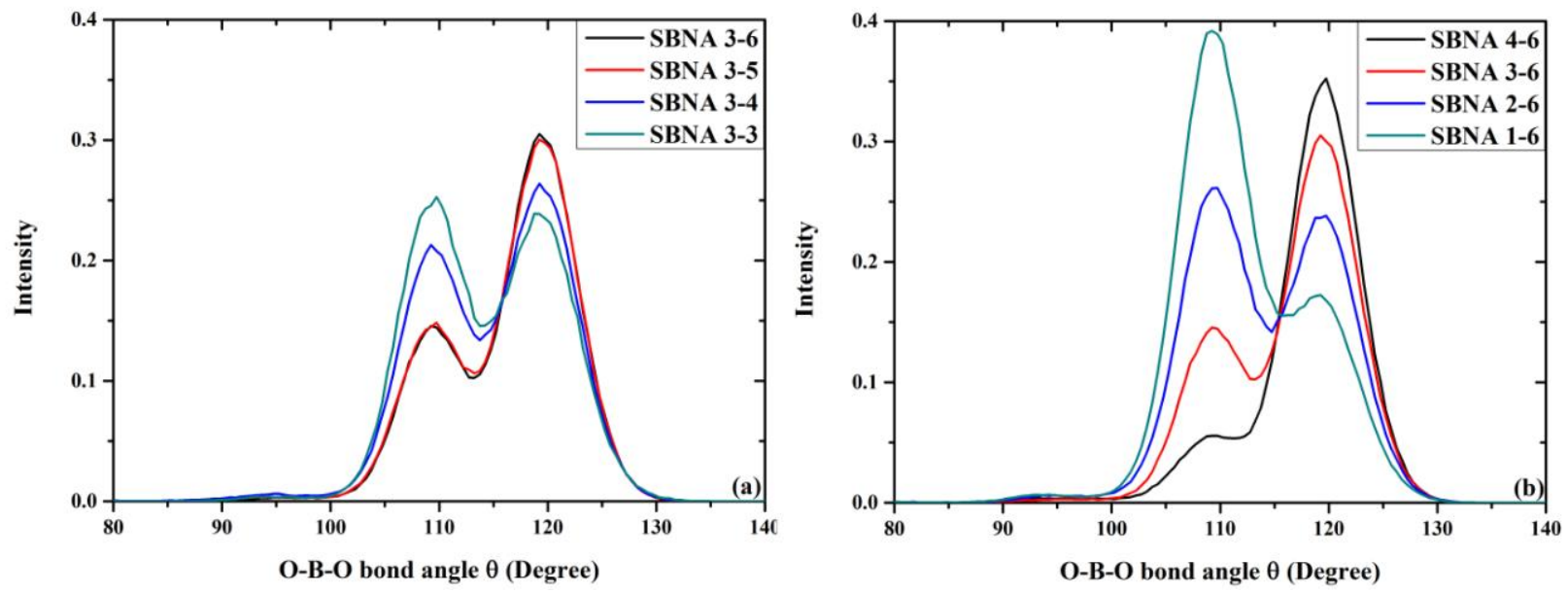

Figure $10 \mathrm{O}-\mathrm{B}-\mathrm{O}$ bond angle distribution of sodium boroaluminosilicate glasses with a) same $\mathrm{Al}_{2} \mathrm{O}_{3}$ content and $b$ ) same $\mathrm{B}_{2} \mathrm{O}_{3}$ content. The glass compositions are SBNA x-y: $16 \mathrm{Na}_{2} \mathrm{O}-$ $4 \mathrm{xAl}_{2} \mathrm{O}_{3}-4 \mathrm{yB}_{2} \mathrm{O}_{3}-4(21-\mathrm{x}-\mathrm{y}) \mathrm{SiO}_{2}(\mathrm{x}=1,2,3$ and $\mathrm{y}=3,4,5,6)$.

To give a detailed understanding about the contribution of each boron coordination to the PDF plot of B-O pair and BAD plot of O-B-O angle, both of the plots are decomposed into species of [3]B and [4]B ones (as shown in Figure $11 \mathrm{a}$ ) and b), respectively). The PDF plot gives that the peak position of [3]B-O is at $1.37 \AA$ and the [4]B-O one is at around $1.45 \AA$. The main peaks of O-[3]B-O and O-[4]B-O angle are centered at around $109.5^{\circ}$ and $120.0^{\circ}$, respectively. The peak positions in the decomposed plots agrees well with previous simulation results and experimental data as we discussed above. Therefore, the existence of double main peaks in the B-O PDF and O-B-O PDF plots are results of three and four-coordinated boron.
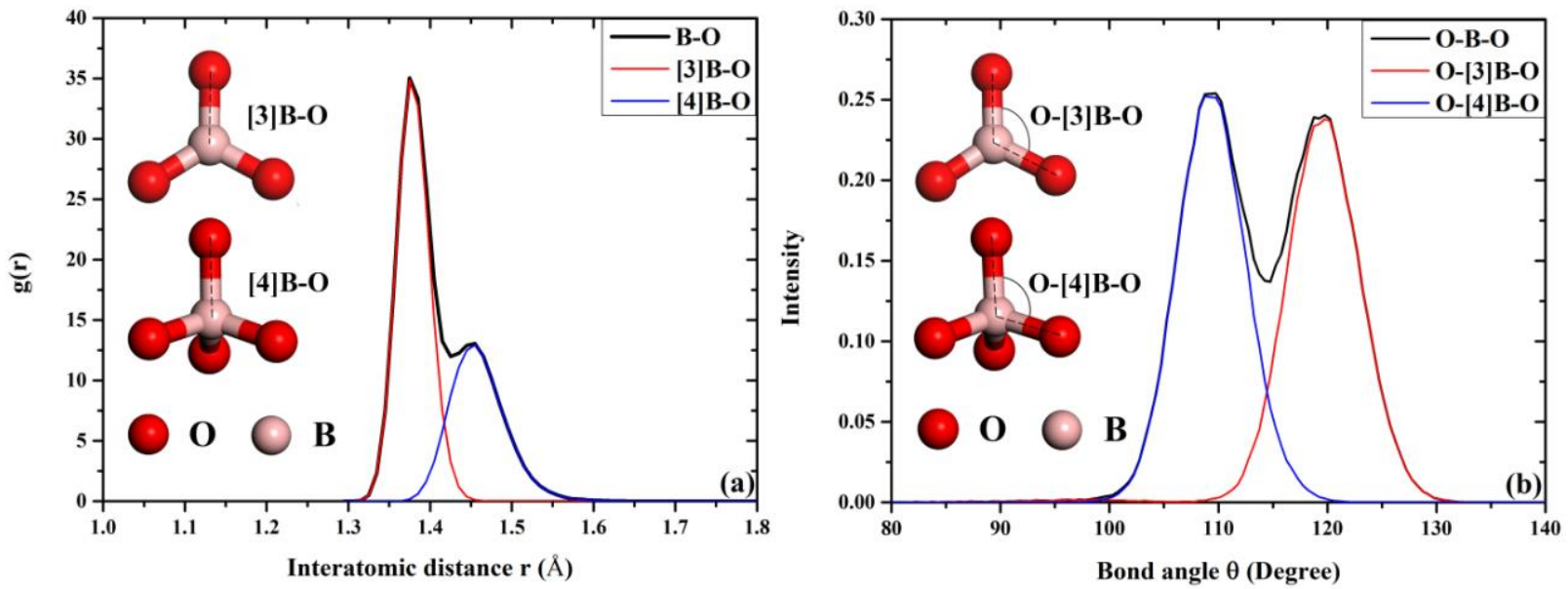
Figure 11 Decomposed plots of a) PDF of B-O pair and b) BAD of O-B-O angle in SBNA 3-3 glasses, respectively.

\subsubsection{Sodium local environments}

The Na-O pair distribution function has been analyzed. The main peak in $\mathrm{Na}-\mathrm{O}$ pair distribution function plot is located at the range from $2.50 \AA$ to $2.52 \AA$. This is consistent with earlier simulations for $\mathrm{Na}_{2} \mathrm{O}-\mathrm{B}_{2} \mathrm{O}_{3}-\mathrm{SiO}_{2}$ ternary systems with the same potentials ${ }^{24}$. It was shown that the $\mathrm{Na}-\mathrm{O}$ distance increases from $2.29 \AA$ to $2.62 \AA$ when the role of the sodium atom changes from a network modifier to a charge compensator. ${ }^{24}$

In order to monitor the structural role of sodium, the percentage of non-bridging oxygen and bridging oxygen as a function of $\frac{\mathrm{Na}_{2} \mathrm{O}-\mathrm{Al}_{2} \mathrm{O}_{3}}{\mathrm{~B}_{2} \mathrm{O}_{3}}$ are shown in Figure 12. For those oxygen around all the glass-former atoms (Figure $12 \mathrm{a}$ )), the majority species is bridging oxygen which is about $92-95 \%$, while about $2-5 \%$ of non-bridging and tri-bridging oxygen exist. However, those values are quite steady while composition varies. Therefore, further analysis of the oxygen species around boron atoms is studied and plotted in Figure $12 \mathrm{~b}$ ). It can be seen that over $80 \%$ of oxygen ions play the role of bridging oxygen and only 5-20\% of them are non-bridging oxygen. This explains why the average Na-O distance (around $2.5 \AA$ ) in the compositions studied in this work is toward the longer side $(2.29$ to $2.62 \AA){ }^{24}$ as majority of sodium ions play the role of charge compensators. The bridging oxygen percentage decreases while the excess sodium content (remaining amount after converting the Al from 5-6 to 4 coordinated) increases, when sodium ions began to play the role of breaking the network linkages by forming non-bridging oxygen ions. The percentage of non-bridging oxygen increases with $\frac{\mathrm{Na}_{2} \mathrm{O}-\mathrm{Al}_{2} \mathrm{O}_{3}}{\mathrm{~B}_{2} \mathrm{O}_{3}}$ and shows the opposite trend of bridging oxygen. Furthermore, the percentage of non-bridging oxygen increases slightly faster with $\frac{\mathrm{Na}_{2} \mathrm{O}-\mathrm{Al}_{2} \mathrm{O}_{3}}{\mathrm{~B}_{2} \mathrm{O}_{3}}$ at the low excess sodium content range than the high excess sodium one. This can be seen from the change of slope before and after 0.5 in Figure 12 b). 

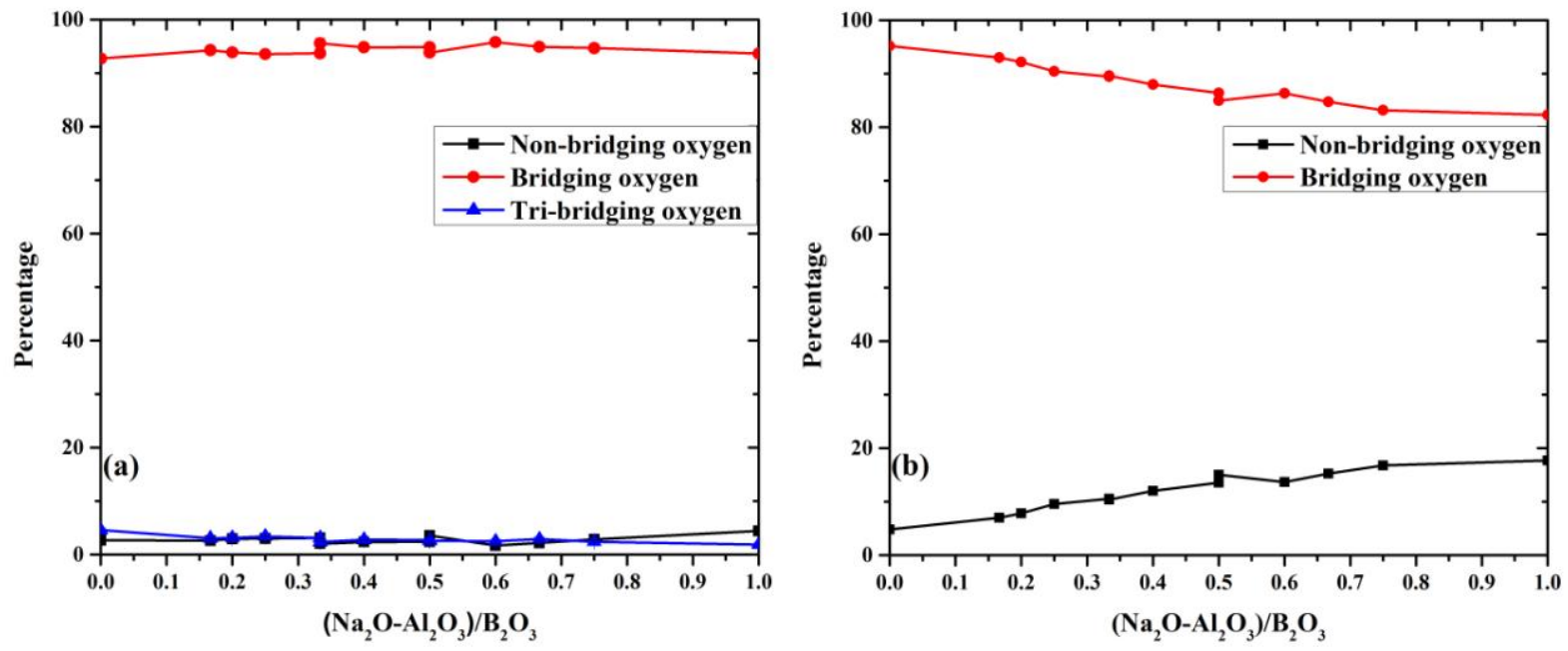

Figure 12 Percentage of oxygen species around a) all the glass-former atoms and b) boron atoms as a function of $\left(\mathrm{Na}_{2} \mathrm{O}-\mathrm{Al}_{2} \mathrm{O}_{3}\right) / \mathrm{B}_{2} \mathrm{O}_{3}$, respectively. The two data points at same value of $\mathrm{x}$ axis correspond to two compositions with same excess sodium content $\left(\mathrm{Na}_{2} \mathrm{O}-\mathrm{Al}_{2} \mathrm{O}_{3} / \mathrm{B}_{2} \mathrm{O}_{3}\right)$. 


\subsection{Network and medium range structures in the glasses}

\subsubsection{Polyhedral connection analysis}

Polyhedral connectivity shows how the network former oxygen polyhedrons are connected hence provides additional information of the network structures. Experimentally, these can be revealed by analyzing multiple quantum ${ }^{17} \mathrm{O}$ NMR spectra ${ }^{52}$. For a glass with three glass formers, there would be six different linkages: $\left[\mathrm{AO}_{\mathrm{n}}\right]-\left[\mathrm{AO}_{\mathrm{n}}\right],\left[\mathrm{AO}_{\mathrm{n}}\right]-\left[\mathrm{BO}_{\mathrm{m}}\right],\left[\mathrm{AO}_{\mathrm{n}}\right]-\left[\mathrm{CO}_{1}\right],\left[\mathrm{BO}_{\mathrm{m}}\right]-\left[\mathrm{BO}_{\mathrm{m}}\right]$, $\left[\mathrm{BO}_{\mathrm{m}}\right]-\left[\mathrm{CO}_{1}\right]$ and $\left[\mathrm{CO}_{1}\right]-\left[\mathrm{CO}_{1}\right]$, which we simplified as $[\mathrm{A}][\mathrm{A}],[\mathrm{A}][\mathrm{B}],[\mathrm{A}][\mathrm{C}],[\mathrm{B}][\mathrm{B}],[\mathrm{B}][\mathrm{C}]$ and $[\mathrm{C}][\mathrm{C}])$. Important information on medium range structure, the preferences of these linkages, can impact glass properties. In order to characterize the connectivity, we defined $P_{A B}$, the probability of a polyhedral linkage $[\mathrm{A}][\mathrm{B}]$, as the ratio between the normalized number of this linkage $([\mathrm{A}][\mathrm{B}])$ and normalized number of the all possible linkages. The normalized value was calculated through dividing the number of the linkage by the number of each linking glass former cation. Hence, the probability of the linkage between glass former cation $\mathrm{A}$ and $\mathrm{B}, P_{A B}$, is defined as,

$P_{A B}=\frac{N_{[A][B]} /\left(N_{A} \times N_{B}\right)}{\sum_{i=A, B, C} \sum_{j=A, B, C}\left(\frac{n}{2} \times N_{[i][j]} /\left(N_{i} \times N_{j}\right)\right)}$

where, $i$ and $j$ represent the glass-forming elements $A, B$ or $C . N_{i}$ and $\mathrm{N}_{j}$ are number of each glass former cation, and $\mathrm{N}_{[\mathrm{i}][j]}$ is the number of the linkages of $i$ and $j$. The parameter n equals to 2 if $i$ is the same as $j$, or equals to 1 if $i$ and $j$ are different.

The preferences of each linkages in sodium boroaluminosilicate glasses, $\left[\mathrm{SiO}_{4}\right]-\left[\mathrm{SiO}_{4}\right]$, $\left[\mathrm{SiO}_{4}\right]-\left[\mathrm{AlO}_{\mathrm{m}}\right],\left[\mathrm{SiO}_{4}\right]-\left[\mathrm{BO}_{\mathrm{n}}\right],\left[\mathrm{BO}_{\mathrm{n}}\right]\left[\mathrm{BO}_{\mathrm{n}}\right],\left[\mathrm{BO}_{\mathrm{n}}\right]\left[\mathrm{AlO}_{\mathrm{m}}\right]$, and $\left[\mathrm{AlO}_{\mathrm{m}}\right]\left[\mathrm{AlO}_{\mathrm{m}}\right]$, have been calculated from the simulated glass configurations and plotted in Figure 13 (a), (b) and (c) for compositions with $\mathrm{x}=1,2$ and 3 , respectively. As shown in all of these three figures, the $P_{\text {SiAl }}$ value is the largest one and the $P_{S i S i}$ value is the lowest one among the probabilities of three linkages which formed by silicon. This indicates that silicon prefer to form a [Si][Al] linkage rather than a $[\mathrm{Si}][\mathrm{B}]$ linkage and the $[\mathrm{Si}][\mathrm{Si}]$ linkage has the lowest probability. On the other hand, the probabilities of the three linkages formed by aluminum decreases in the order of [Si][Al], [Al][Al] and [B][Al]; this means that aluminum prefers forming linkage with silicon, than with itself, and the least with boron. Moreover, probabilities of the linkages formed by 
boron illustrate that the $[\mathrm{Si}][\mathrm{B}]$ linkage is the most preferred one, $[\mathrm{B}][\mathrm{B}]$ linkage is the second one and $[\mathrm{B}][\mathrm{Al}]$ is the last one. Among all the linkages, $[\mathrm{Si}][\mathrm{Al}]$ is the most probable one and $[\mathrm{Al}][\mathrm{B}]$ is the least probable one. Furthermore, with the same sodium and aluminum contents (same x), increasing boron content gives lower $P_{S i B}$ values; whereas, the $P_{S i A l}$ value and $P_{A l A l}$ one increase.

Moreover, the results show that the probabilities of the [Si][Al] linkages are around 0.33 for all the compositions. They are higher than the combination ones of the [Si][Si] and [Al][Al] linkages, which range from 0.1 to 0.2 . This result suggests that [Si][Al] linkages are statistically more favorable as compared to the other two. This is in agreement with the "aluminum avoidance" or the Loewenstein's rule ${ }^{53}$, and has been observed in both the previous theoretical calculations and NMR experiments ${ }^{54,55}$.
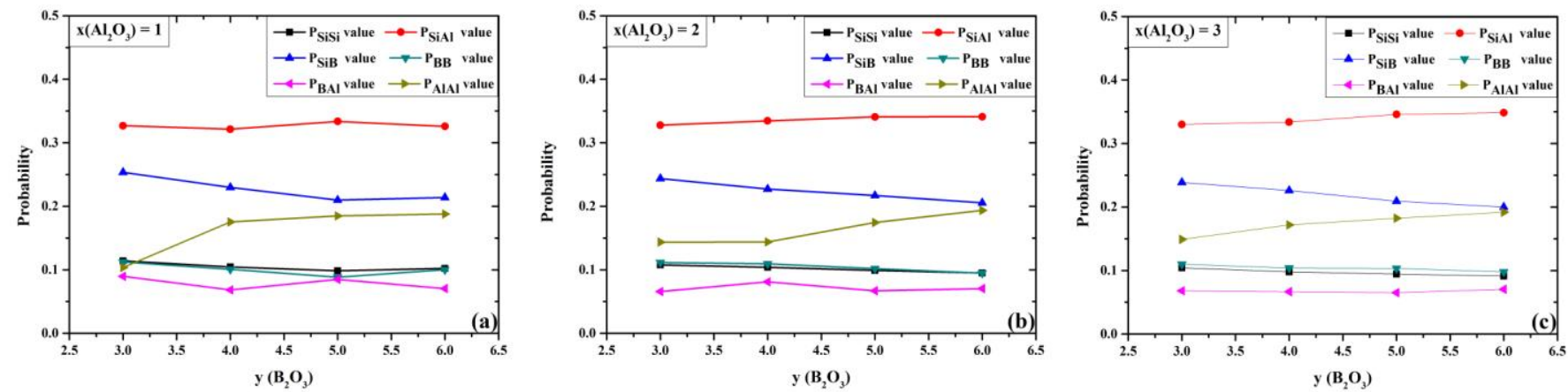

Figure 13 Preferences of [Si][Si], [Si][Al], [Si][B], [B][B], [B][Al] and [Al][Al] linkages for a) $x=1, b) x=2$ and c) $x=3$, respectively. The formula of these glasses is $16 \mathrm{Na}_{2} \mathrm{O}-4 \mathrm{xAl}_{2} \mathrm{O}_{3}-4 \mathrm{yB}_{2} \mathrm{O}_{3^{-}}$ $4(21-x-y) \mathrm{SiO}_{2}(x=1,2,3,4$ and $y=3,4,5,6)$.

Figure 14 illustrates the probability of linkages for compositions with the same soda and silica contents: a) and b) are for $x+y=6$ and $x+y=7$, respectively. Again in these two series, [Si][Al] has the highest probability and $[\mathrm{Al}][\mathrm{B}]$ has lowest probability. It is also shown that the probability of the $[\mathrm{Si}][\mathrm{Si}],[\mathrm{Si}][\mathrm{Al}]$ and $[\mathrm{B}][\mathrm{B}]$ linkages almost remain constant when alumina is increased and, at the same time, boron oxide is decreased. With decreasing boron oxide (and increasing alumina) concentrations, the probability of the $[\mathrm{Si}][\mathrm{B}]$ linkages slightly increases while that of the $[\mathrm{B}][\mathrm{Al}]$ linkages slightly decreases. Furthermore, increasing alumina (reducing boron oxide) leads to slight decrease of the probability of the [Al][Al] linkages. 

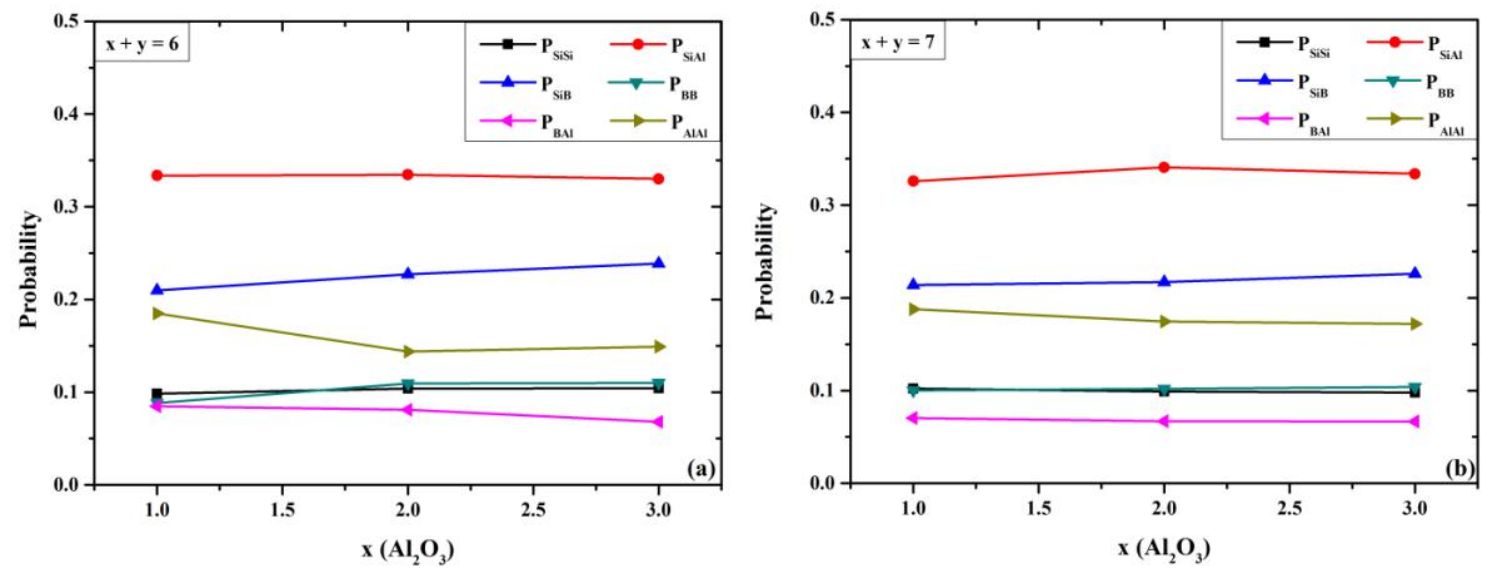

Figure 14 Preferences of [Si][Si], [Si][Al], [Si][B], [B][B], [B][Al] and [Al][Al] linkages for compositions with two different values of Si content: a) for $x+y=6$ ones and b) for $x+y=7$ ones, respectively. The formula of the glasses is $16 \mathrm{Na}_{2} \mathrm{O}-4 \mathrm{xAl}_{2} \mathrm{O}_{3}-4 \mathrm{yB}_{2} \mathrm{O}_{3}-4(21-\mathrm{x}-\mathrm{y}) \mathrm{SiO}_{2}(\mathrm{x}=1$, $2,3,4$ and $\mathrm{y}=3,4,5,6)$.

\subsubsection{Ring size distribution}

Primitive ring size distributions of network forming glasses provide characteristic information of the medium range structures ${ }^{17,56}$. For silica, it has a symmetric distribution with a peak at around 6 membered rings. With the addition of modifiers such as sodium oxide, larger rings are created and, at the same time, the intensity of the major peak decreases ${ }^{17}$. The primitive ring size distributions of the sodium boroaluminosilicate glasses were analyzed and the results are shown in Figure 15 a), b) and c). In these analyses, we considered the linkages of all the three glass formers. These were done through evaluating the Si-O, B-O and Al-O linkages with different cutoffs obtained from the first peak minimum from their corresponding pair distribution functions. The results show the ring size distributions of the mixed former glasses have generally symmetric distributions ranging from 3 to 13 membered rings, with a broad peak centered at around 7 membered rings. With the constant soda concentration $(16 \mathrm{~mol} \%)$ of the glasses studied, the change of the ring size distribution with composition is relatively small. There are, however, some noticeable trend exists. For glasses with same boron content (Figure 15 a)), increasing alumina (decreasing silica) leads to a lower peak intensity and slightly broader peak, as well as small right shift of the peak position from 7 to 8-9. This indicates that silica is stronger glass- 
former comparing with alumina. For glasses with same silicon content (shown in Figure 15 b)), the position and shape of the peak stay the same. For glasses with same alumina (shown in Figure 15 c)), the peak intensity slightly decreases and the shape becomes border while increasing boron oxide content (decreasing silica); meanwhile, the peak position slightly shifts to the right. That is, the silica has the strongest network forming ability. In general, the ring size distribution show that all the three glass formers link together to form the three dimensional network similar to that of silica. This result agrees well with previous simulation results of sodium aluminosilicate glasses ${ }^{7}$.
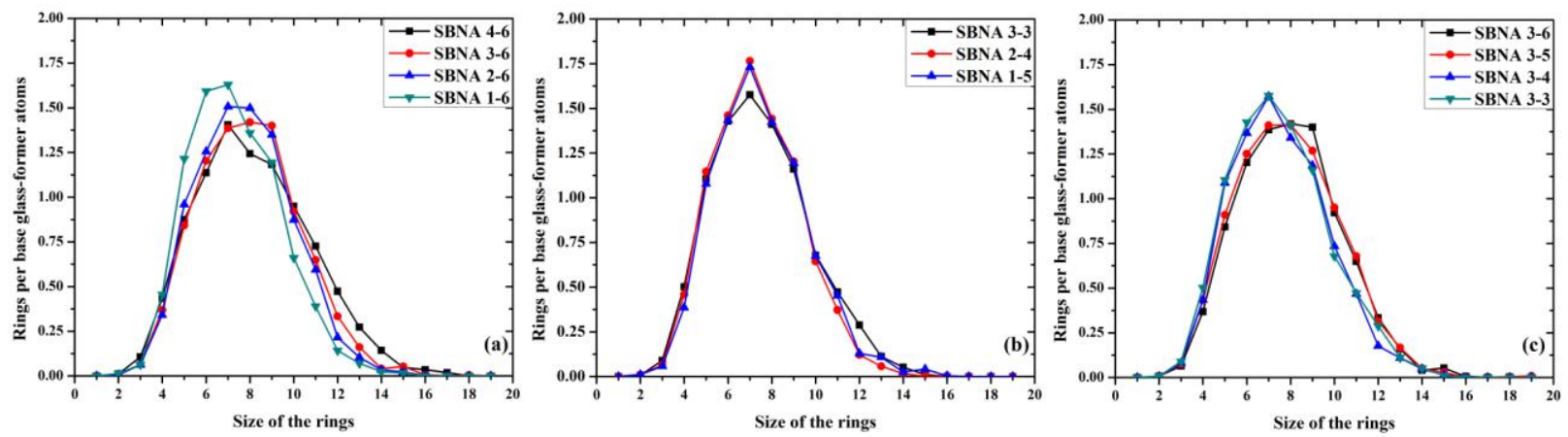

Figure 15 Primitive ring size distribution of sodium boroaluminosilicate glasses for compositions with a) same boron oxide, b) same silica and c) same alumina contents, respectively. The rings were calculated assuming linkages of all glass formers: $\mathrm{SiO}_{2}, \mathrm{~B}_{2} \mathrm{O}_{3}$, and $\mathrm{Al}_{2} \mathrm{O}_{3}$. The formula of the glasses is $16 \mathrm{Na}_{2} \mathrm{O}-4 \mathrm{xAl}_{2} \mathrm{O}_{3}-4 \mathrm{yB}_{2} \mathrm{O}_{3}-4(21-\mathrm{x}-\mathrm{y}) \mathrm{SiO}_{2}(\mathrm{x}=1,2,3,4$ and $\mathrm{y}=3,4,5,6)$.

\subsection{Physical properties of boroaluminosilicate glasses}

\subsubsection{Vibrational spectra}

Vibrational density of states (VDOS) can be calculated from static or dynamic methods and present important information for infrared, Raman or inelastic neutron spectra interpretation. In this work, the VDOS was obtained from Fourier transformation of velocity autocorrelation function at $300 \mathrm{~K}$. The VDOS plots for a series of glass compositions with the same sodium and silicon contents (i.e. the same $x+y$ value) are shown in Figure 16 (left side: a-f). The VDOS values are normalized to 1 for better comparison. The VDOS from classical MD simulations show similar total and partial spectra features as compared to ab initio simulations but the frequency from classical simulations systematically shifted to higher frequency. Similar results 
were found in earlier comparison of classical and $a b$ initio vibrational spectra. In order to directly compare with previous $a b$ initio results $^{27}$, the frequency from classical simulations is rescaled to 2/3 of the original values; moreover, the ab initio plots are also shown in Figure 16 (right side : a) and b)) for better comparison. Four major peaks of the total VDOS are observed in the top plots (Figure 16 left side: a), c) and e)): the first one is from 0 to $565 \mathrm{~cm}^{-1}$, the second one is from 565 $\mathrm{cm}^{-1}$ to $948 \mathrm{~cm}^{-1}$, the third one from $948 \mathrm{~cm}^{-1}$ to $1200 \mathrm{~cm}^{-1}$ and the forth one is from $1200 \mathrm{~cm}^{-1}$ to $1600 \mathrm{~cm}^{-1}$. These peak regions are quite close to those values observe in sodium borosilicate system in previous simulation study ${ }^{27}$ (as shown in Figure 16 right side: a) and b)), which are 0$600 \mathrm{~cm}^{-1}, 600-820 \mathrm{~cm}^{-1}, 820-1200 \mathrm{~cm}^{-1}$ and 1200-1600 $\mathrm{cm}^{-1}$, respectively. Detailed observation tells that the first peak is mainly contributed by sodium, oxygen, silicon and aluminum partial VDOS; whereas the boron one is relatively weak. The second peak mainly consists of the oxygen, silicon and boron partial VDOS, while the third and fourth peaks are mainly contributed by the oxygen and boron ones. This tells that the oxygen partial VDOS form the major frame of the total VDOS spectrum, while sodium one has no high frequency effect. The aluminum and silicon effects only exist in low and medium frequency regions; whereas, the boron one gives the effect during the whole range especially at medium and high frequency regions. These observations are generally in good agreement with previous simulation results for sodium borosilicate glass ${ }^{27}$, $45 \mathrm{~S} 5$ bioactive glass ${ }^{57}$, and lithium silicate glass ${ }^{38}$. It's worth noting that the sodium partial VDOS peak is centered at $56 \mathrm{~cm}^{-1}$ which is lower than the value in previous ab initio and MD simulation results ${ }^{27,57}$.

In order to understand the contributions of ${ }^{[3]} \mathrm{B}$ and ${ }^{[4]} \mathrm{B}$ units to the total boron VDOS, the decomposed boron partial VDOS plots for the same glasses are normalized to 1 and given in Figure 16 left side: b), d) and f). The first main peak of ${ }^{[3]} \mathrm{B}$ VDOS is from 0 to $581 \mathrm{~cm}^{-1}$, and the second one is from 1200 to $1600 \mathrm{~cm}^{-1}$. This indicates the low and high frequency effects of boron VDOS are mainly caused by the ${ }^{[3]} \mathrm{B}$ units. On the other hand, the main peak of ${ }^{[4]} \mathrm{B}$ VDOS is a boarder peak ranging from $500 \mathrm{~cm}^{-1}$ to $1600 \mathrm{~cm}^{-1}$, and it corresponds to the peak in medium frequency range of the total boron VDOS. The increase of the fraction of four-coordinated boron enhances the intensity of the main peak of ${ }^{[4]} \mathrm{B}$ VDOS and that of ${ }^{[3]} \mathrm{B}$ VDOS follows the opposite trend. As a result, the VDOS plots we calculated have the trend generally in good agreement with previous simulation results ${ }^{27,38,57}$, but some of the peak positions diverge from those in $a b$ initio calculations ${ }^{27}$ for ternary systems which may be caused by additional aluminum 
content.
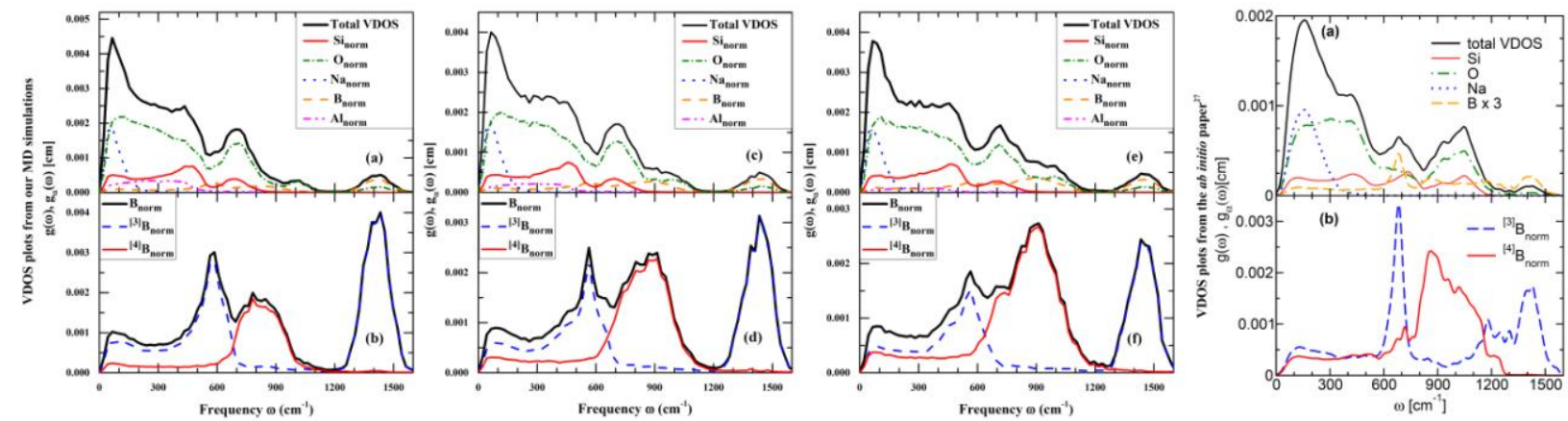

Figure 16 Vibrational density of states (VDOS) plots: Left side a-f are from our MD simulations, and the right side $a-b$ is from the $a b$ initio calculations ${ }^{27}$ for comparison. For our MD ones, from left to right are for compositions with same silicon content: SBNA3-4, SBNA2-5 and SBNA1-6, respectively. The top plots (a, c and e) are total and partial VDOS of the glasses with the values normalized to 1 for better comparison. The bottom ones (b, $d$ and f) are normalized partial VDOS of trigonal ${ }^{[3]} \mathrm{B}$ and tetragonal ${ }^{[4]} \mathrm{B}$ atoms together with the normalized partial boron VDOS. The formula of the glasses is $16 \mathrm{Na}_{2} \mathrm{O}-4 \mathrm{xAl}_{2} \mathrm{O}_{3}-4 \mathrm{yB}_{2} \mathrm{O}_{3}-4(21-\mathrm{x}-\mathrm{y}) \mathrm{SiO}_{2}(\mathrm{x}=1,2,3,4$ and $\mathrm{y}=3,4,5,6)$.

\subsubsection{Mechanical properties}

Mechanical properties were calculated by applying strains in six different directions. By using the finite difference method, the elastic constants were first obtained and mechanical properties such as bulk modulus, shear modulus, Young's modulus were then calculated by using Hill's method ${ }^{40}$ (Eqs. 18-22). The comparison between the experimental values ${ }^{43}$ and the calculated values are shown in Figure 17. It is worth mentioning that there is an outlier of the bulk modulus values which can be due to input of Poisson's ratio in the calculation. The shear and Young's moduli were from experiments and bulk moduli were calculated with the two moduli together with the Poisson's ratio. As shown in the figure, the mechanical property values of our simulated glass structures reproduced well of the trend of the experimental values as a function of $R_{e}^{*}$ for all four series with the different $\mathrm{x}\left(\mathrm{Al}_{2} \mathrm{O}_{3}\right.$ mol\%) values, with the differences between the simulated and experimental values being within 10GPa for most compositions. The difference is larger for high $R_{e}^{*}$ range with compositions of lower x values (i.e. lower alumina 
and hence higher boron oxide concentrations) which can be explained by the higher $\mathrm{N}_{4}$ values of boron as shown in Figure 6. Furthermore, with same sodium and silicon content (same $x+y$ ), decreasing alumina (increasing boron oxide content) increases all three moduli. Moreover, with the same sodium and boron content (same y), increasing aluminum (and hence decreasing silica content) also reduces the mechanical moduli of these glass systems. Based on the experimental data and most of our simulation results (mainly the series of $x=2$ and $x=3$ ), with the same sodium and aluminum content (same $\mathrm{x}$ ), increasing boron content (and decreasing silica content) lowers the moduli. As a result, the order of contribution to mechanical properties among the three glass formers is: silica > boron oxide > alumina.
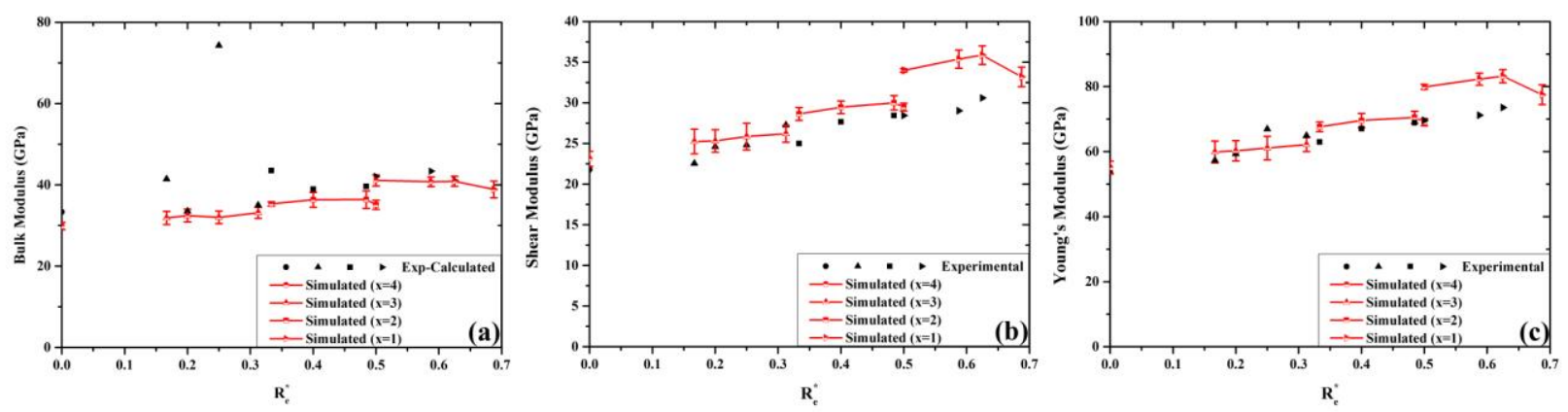

Figure 17 Comparison of calculated and experimental mechanical properties. (a) Bulk modulus, b) shear modulus and c) Young's modulus comparisons between the experimental data and simulated results, respectively. Error bar for simulations were calculated from standard deviations of six glasses simulated. Experimental shear modulus and Young's modulus values are from Gan et al. ${ }^{43}$, while the bulk modulus are calculated using equation 22 . The $R_{e}^{*}$ value is calculated through equation 10, and listed in Table 4.

\section{Discussions}

\subsection{Validation and testing of the borosilicate and boroaluminosilicate potentials.}

In order to validate the original potentials by Kieu et al [23] for borosilicate glasses, we have simulated sodium borosilicate glasses in wide composition ranges using MD simulations. The limitation of the original potential set was also investigated by analyzing the composition dependent of the potential parameters.

One of the two characters of the potential for boron containing glasses is the composition dependent A parameters (equation 4) for B-O interactions ${ }^{24}$. Careful examination of the potential 
parameters found that there are certain composition regions, mainly those with high silica concentration, that the original potential failed to provide reasonable boron coordination. This is mainly due to the unreasonable "A" parameter for the B-O pair interactions (denoted as $\mathrm{A}_{\mathrm{B}-\mathrm{O}}$ ). This is shown in Figure 18 where $A_{B-O}$ is plotted against $R^{*}$. The $A_{B-O}$ value first increases slowly with $\mathrm{R}^{*}$, based on the concept that $\mathrm{A}_{\mathrm{B}-\mathrm{O}}$ is composition dependent to correctly reproduce the coordination number change of $B$. When the $R^{*}$ value is larger than 0.78 , the $A_{B-O}$ value begins to decrease which leads to slightly shorter B-O bond distance. This situation becomes severe when the $\mathrm{R}^{*}$ value is larger than 0.9 . When the $\mathrm{R}^{*}$ value is larger than 1.2 , the $\mathrm{A}_{\mathrm{B}-\mathrm{O}}$ becomes extremely small and even negative once the $\mathrm{R}^{*}$ value is larger than 1.27 . These led to unphysical B-O bonding and coordination in certain composition ranges. This limits MD simulations of certain compositions with high silica and high soda concentrations.

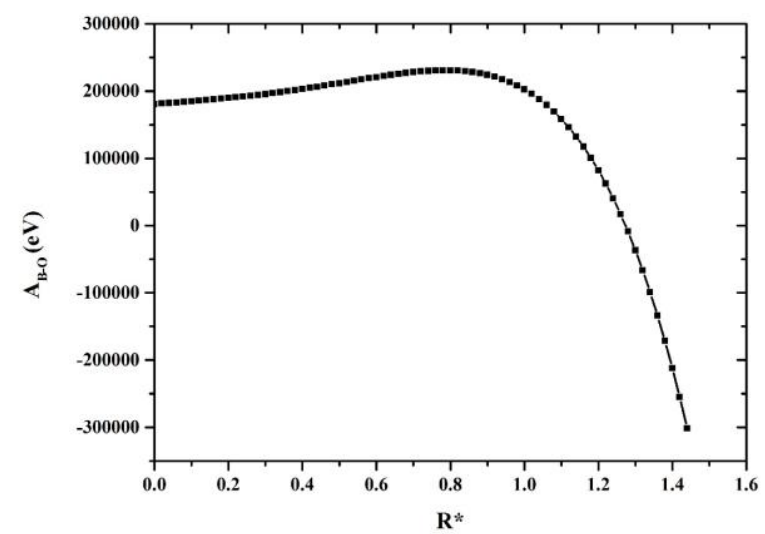

Figure $18 \mathrm{~A}_{\mathrm{B}-\mathrm{O}}$ as a function of $\mathrm{R}^{*}$ curve for borosilicate glasses obtained by solving Eq. 4

To describe the conversion of boron coordination between three-fold $\left(\mathrm{N}_{3}\right)$ and four-fold $\left(\mathrm{N}_{4}\right)$, we tested two series of compositions (for $\left[\mathrm{SiO}_{2}\right] /\left[\mathrm{B}_{2} \mathrm{O}_{3}\right]=1$ and 2, respectively) and marked them as the dots shown in the composition triangle. The details of the compositions can be found in the Appendix (Table 2). The glass structures were generated using the procedures described in section 2. Each composition had around 3000 atoms. The simulated structures showed compositional dependence of boron coordination with distributions of 3 and 4 coordinated B. The values of averaged B coordination numbers and those from the Yun, Dell and Bray ${ }^{10,11}$ model are also listed in the Appendix Table 2. The results show that most differences of boron 
coordination are within $4 \%$ with the model. Base on the YDB model, the $\mathrm{R}_{\max }$, which

numerically equals to $\frac{K}{16}+0.5$, is the $\mathrm{R}$ value at which $\mathrm{N}_{4}$ reaches a plateau. For $\mathrm{R}$ below $\mathrm{R}_{\max }$, the simulation properly reproduced the linear relationship of ${ }^{[4]} \mathrm{B}$ with $\mathrm{R}$. There is, however, a difference of the exact location of the $\mathrm{R}_{\max }$ and existence of some discrepancy between the simulated one and the one from model for high $\mathrm{R}$ values.

Together with favorable comparison of mechanical properties and other structural features such as B-O and Si-O distances, it can be concluded that the Kieu et al. [23] potential set can generate reasonable glass structures of the borosilicate glasses in wide composition ranges. It is, however, worth noting that in some compositions, especially high silica compositions regions, the potential would not be able to correctly describe boron environment due to unphysical A values of B-O short range interactions. In addition, the difference of theoretical and simulated percentage of ${ }^{[4]} \mathrm{B}$ is found to be larger at high $\mathrm{R}$ (i.e. $\mathrm{Na}_{2} \mathrm{O} / \mathrm{B}_{2} \mathrm{O}_{3}$ ratio) values than lower $\mathrm{R}$ ones. Since the development of potentials for boroaluminosilciate glasses of this work is based on the borosilicate potentials by Kieu et al. ${ }^{24}$, the newly developed potentials would inherit some of these limitations. As the boroaluminosilciate glass compositions studied in this paper are away from these regions so the validity of the results is not influenced. Nevertheless, these critical analyses also point out directions of improvement of the current potential system, which we are currently working on and will be reported in future publications.

\subsection{Comparisons of theoretical models: Dell and Bray model, Du and Stebbins model and Two state model}

The structures of sodium boroaluminosilicate glasses are complicated due to the interaction of the structural units generated by the three glass network formers. One major difficulty for MD simulations to reproduce reasonable structures of this kind of glasses is lacking of parameters to describe the three to four coordination conversion of boron $\left(\mathrm{N}_{4}\right)$. For the ternary systems (alkali borosilicate glass), Yun, Dell and Bray ${ }^{10,11}$ proposed a model to estimate the four-coordinated boron percentage based on NMR studies. Kieu et al ${ }^{24}$,therefore, developed a compositiondependent empirical potential to simulate the ternary systems by fitting parameters based on the YDB model. However, the situation becomes even more complicated when come to the quaternary systems, since increasing aluminum content induces the competition between boron and aluminum for oxygen and charge compensating sodium ions. El Damrawi and Gohar's ${ }^{12}$ 
replaced $\mathrm{R}$ in ternary system by $\mathrm{R}^{\prime}=\left(\mathrm{Na}_{2} \mathrm{O}-\mathrm{Al}_{2} \mathrm{O}_{3}\right) / \mathrm{B}_{2} \mathrm{O}_{3}$ in the quaternary systems, and noticed that the four-coordinated boron percentage in the quaternary systems at low sodium concentration is much lower than the one in the ternary systems. Du and Stebbins ${ }^{8}$ then proposed a modified YDB model by treating aluminum as boron since they have similar network mixing behavior. Most recently, Smedskjaer et al ${ }^{6}$ proposed a temperature-dependent constraint model, two-state model, to calculate the four-coordinated boron percentage of sodium borosilicate glasses. In order to handle the competition between boron coordination conversion and non-bridging oxygen formation, the glass transition temperature and the enthalpy difference between the two states are took into consideration. This model generally gives better estimation of the $\mathrm{N}_{4}$ value comparing with the YDB model and D\&S model. However, experimental measurement of the $\mathrm{T}_{\mathrm{g}}$ makes this model a little bit complicated, since the rest two model can be calculated directly for certain compositions without any other information.

\subsection{Relationship between glass composition and properties}

For sodium aluminosilicate glasses, one interesting phenomenon is the so-called "aluminum avoidance", or, the Loewenstein's rule ${ }^{53}$. This can be expressed that the linkage Al$\mathrm{O}-\mathrm{Si}$ is more favorable than the combination of Al-O-Al and Si-O-Si linkages. In our simulations, we calculated the normalized probabilities of forming these three linkages in sodium boroaluminosilicate glasses (as shown in Figure 13 and Figure 14), and the simulation results show that the probability of forming Al-O-Si linkages is much higher than the combination of the $\mathrm{Al}-\mathrm{O}-\mathrm{Al}$ and $\mathrm{Si}-\mathrm{O}-\mathrm{Si}$, with B-O-Al having the lowest probability of linkages. Thus our results support the "aluminum avoidance" phenomenon exists in both ternary and quaternary systems.

It was found that many structural features and properties of the boroaluminosilicate glasses depend on the glass composition and these dependences can be correlated to key structure features such as the percentage of silica or the percentage of four-fold coordinated boron. This is not surprising as silica is the strongest network-former among $\mathrm{Al}_{2} \mathrm{O}_{3}, \mathrm{~B}_{2} \mathrm{O}_{3}$ and $\mathrm{SiO}_{2}$. As we have shown earlier, addition of small amount of silica can covert aluminum from 5- and 6-fold coordination to 4-fold coordination and make them play a glass former role in rare earth aluminosilicate glasses ${ }^{58}$. Furthermore, four-fold coordinated boron also have a strong effect on the properties. For example, the elastic and bulk moduli of several series of the glasses were found to increase with the percentage of ${ }^{4} \mathrm{~B}$ (as shown in Figure 17). 


\section{Conclusions}

In this paper, a set of self-consistent, compositionally dependent partial charge potentials have been developed for atomistic simulations of multi-component oxide glasses with three common glass formers: $\mathrm{SiO}_{2}, \mathrm{~B}_{2} \mathrm{O}_{3}$ and $\mathrm{Al}_{2} \mathrm{O}_{3}$ based on the framework of the borosilicate system proposed by Kieu et al. The aluminum related potential parameters were introduced based on the current understanding of the glass chemistry and the parameters obtained by fitting to structures and properties of crystalline and model glass compositions. The newly developed potentials were then used to study several series of sodium boroaluminosilicate glasses $16 \mathrm{Na}_{2} \mathrm{O}-4 \mathrm{xAl}_{2} \mathrm{O}_{3}$ $4 \mathrm{yB}_{2} \mathrm{O}_{3}-4(21-\mathrm{x}-\mathrm{y}) \mathrm{SiO}_{2}(\mathrm{x}=1,2,3,4$ and $\mathrm{y}=3,4,5,6)$ with varying ratios of glass formers but constant modifier concentrations. Careful comparison of both the short and medium range structures of these glasses were performed with available experimental data as well ab initio simulation results. It is shown this set of potential set can reproduce the coordination change of aluminum and boron as a function of composition. In addition, the mechanical properties are also in good agreement with experimental values, while the calculated vibrational spectra trend agrees well with previous ab initio simulation results. It is concluded that the developed composition-dependent partial charge pair-wise potentials are capable to deal with complex structure changes of boroaluminosilicate glasses and describe the properties. Importantly, these potentials are computationally efficient and can be employed to study simulation of large systems (e.g. millions of atoms) and obtain long time (e.g. nano to micro seconds) properties of glass, glass melts and glass formation/transition behaviors, which ab initio calculations cannot handle easily. Lastly, the limitation of these potential was also discussed and directions of future improvement pointed out.

\section{Acknowledgement:}

This work was supported by DOE NEUP (project \# DE-NE000748) and NSF DMR Ceramics program (project \# 1508001). 


\section{References:}

${ }^{1}$ H.G. Pfaender, Schott Guide to Glass (Springer Science \& Business Media, 2012).

${ }^{2}$ G.H. Beall, D.A. Duke, D.R. Uhlmann, and N.J. Kreidl, Acad. Press. New York 1, 403 (1983).

${ }^{3}$ L.D. Pye, V.D. Fréchette, and N.J. Kreidl, Borate Glasses: Structure, Properties, Applications (Springer Science \& Business Media, 2012).

${ }^{4}$ M.M. Smedskjaer, R.E. Youngman, and J.C. Mauro, Appl. Phys. A 116, 491 (2014).

5 J. Du, in Mol. Dyn. Simulations Disord. Mater. (Springer, 2015), pp. 157-180.

${ }^{6}$ M.M. Smedskjaer, J.C. Mauro, R.E. Youngman, C.L. Hogue, M. Potuzak, and Y. Yue, J. Phys. Chem. B 115, 12930 (2011).

${ }^{7}$ Y. Xiang, J. Du, M.M. Smedskjaer, and J.C. Mauro, J. Chem. Phys. 139, 44507 (2013).

${ }^{8}$ L.-S. Du and J.F. Stebbins, J. Non. Cryst. Solids 351, 3508 (2005).

${ }^{9}$ O. V. Mazurin, J. Non. Cryst. Solids 351, 1103 (2005).

${ }^{10}$ Y.H. Yun and P.J. Bray, J. Non. Cryst. Solids 27, 363 (1978).

${ }^{11}$ W.J. Dell, P.J. Bray, and S.Z. Xiao, J. Non. Cryst. Solids 58, 1 (1983).

${ }^{12}$ G. El-Damrawi, W. Müller-Warmuth, H. Doweidar, and I.A. Gohar, Phys. Chem. Glas. 34, 52 (1993).

${ }^{13}$ J.M. Delaye, V. Louis-Achille, and D. Ghaleb, J. Non. Cryst. Solids 210, 232 (1997).

${ }^{14}$ L. Cormier, D. Ghaleb, D.R. Neuville, J.-M. Delaye, and G. Calas, J. Non. Cryst. Solids 332, 255 (2003).

${ }^{15}$ L. Huang and J. Kieffer, J. Chem. Phys. 118, 1487 (2003).

${ }^{16}$ L. Huang and J. Kieffer, Phys. Rev. B 74, 224107 (2006).

${ }^{17}$ J. Du and A.N. Cormack, J. Non. Cryst. Solids 349, 66 (2004).

18 J. Du and A.N. Cormack, J. Am. Ceram. Soc. 88, 2532 (2005).

${ }^{19}$ J. Du, L. Kokou, J.L. Rygel, Y. Chen, C.G. Pantano, R. Woodman, and J. Belcher, J. Am. Ceram. Soc. 94, 2393 (2011).

${ }^{20}$ L. Kokou and J. Du, J. Non. Cryst. Solids 358, 3408 (2012).

${ }^{21}$ A. Pedone, G. Malavasi, M.C. Menziani, A.N. Cormack, and U. Segre, J. Phys. Chem. B 110, 11780 (2006).

${ }^{22}$ B. Park, Molecular Dynamics Study of the Structure of Borate Glasses, thesis, Alfred University, 1998.

${ }^{23}$ H. Inoue, A. Masuno, and Y. Watanabe, J. Phys. Chem. B 116, 12325 (2012). 
${ }^{24}$ L.-H. Kieu, J.-M. Delaye, L. Cormier, and C. Stolz, J. Non. Cryst. Solids 357, 3313 (2011).

${ }^{25}$ G. Ferlat, T. Charpentier, A.P. Seitsonen, A. Takada, M. Lazzeri, L. Cormier, G. Calas, and F. Mauri, Phys. Rev. Lett. 101, 65504 (2008).

${ }^{26}$ L. Pedesseau, S. Ispas, and W. Kob, Phys. Rev. B 91, 134201 (2015).

${ }^{27}$ L. Pedesseau, S. Ispas, and W. Kob, Phys. Rev. B 91, 134202 (2015).

${ }^{28}$ B. Guillot and N. Sator, Geochim. Cosmochim. Acta 71, 4538 (2007).

${ }^{29}$ B.W.H. Van Beest, G.J. Kramer, and R.A. Van Santen, Phys. Rev. Lett. 64, 1955 (1990).

${ }^{30}$ M. Matsui, Geophys. Res. Lett. 23, 395 (1996).

${ }^{31}$ V. V Maslyuk, T. Bredow, and H. Pfnür, Eur. Phys. J. B-Condensed Matter Complex Syst. 41, 281 (2004).

${ }^{32}$ K.D. Kwon and L.J. Criscenti, J. Mineral. Soc. Korea 26, 119 (2013).

33 J.D. Gale and A.L. Rohl, Mol. Simul. 29, 291 (2003).

${ }^{34}$ I.T. Todorov, W. Smith, K. Trachenko, and M.T. Dove, J. Mater. Chem. 16, 1911 (2006).

${ }^{35}$ D. Chandler, Introduction to Modern Statistical Mechanics (1987).

${ }^{36}$ A.K. Varshneya, Fundamentals of Inorganic Glasses: Arun K. Varshneya (Access Online via Elsevier, 1994).

${ }^{37}$ Y. Xiang, Computational Studies on Structures and Ionic Diffusion of Bioactive Glasses, phdthesis, UNIVERSITY OF NORTH TEXAS, 2014.

${ }^{38}$ J. Du and L.R. Corrales, J. Chem. Phys. 125, 114702 (2006).

${ }^{39}$ S. Plimpton, J. Comput. Phys. 117, 1 (1995).

${ }^{40}$ R. Hill, Proc. Phys. Soc. A 65, 349 (1952).

${ }^{41}$ V. Kahlenberg and H. Böhm, Am. Mineral. 83, 631 (1998).

${ }^{42}$ M. He, X.L. Chen, T. Zhou, B.Q. Hu, Y.P. Xu, and T. Xu, J. Alloys Compd. 327, 210 (2001).

${ }^{43}$ F. Gan, Issledovanie Alyumo-Bornoi Anomalii Svoistv Silikatnykh Stekol, thesis, Leningrad, 1959.

${ }^{44}$ D.M. Zirl and S.H. Garofalini, J. Am. Ceram. Soc. 73, 2848 (1990).

${ }^{45}$ G.N. Greaves, A. Fontaine, P. Lagarde, D. Raoux, and S.J. Gurman, Nature 293, 611 (1981).

${ }^{46}$ R.-S. Zhou and R.L. Snyder, Acta Crystallogr. Sect. B Struct. Sci. 47, 617 (1991).

${ }^{47}$ C.W. Burnham and M.J. Buerger, Zeitschrift Für Krist. Mater. 115, 269 (1961).

${ }^{48}$ N. Ishizawa, T. Miyata, I. Minato, F. Marumo, and S. Iwai, Acta Crystallogr. Sect. B Struct. Crystallogr. Cryst. Chem. 36, 228 (1980). 
${ }^{49}$ D.A. McKeown, G.A. Waychunas, and G.E. Brown, J. Non. Cryst. Solids 74, 349 (1985).

${ }^{50}$ D.A. McKeown, G.A. Waychunas, and G.E. Brown, J. Non. Cryst. Solids 74, 325 (1985).

${ }^{51}$ R.L. Mozzi and B.E. Warren, J. Appl. Crystallogr. 3, 251 (1970).

${ }^{52}$ S. Wang and J.F. Stebbins, J. Am. Ceram. Soc. 82, 1519 (1999).

${ }^{53}$ W. Loewenstein, Am. Mineral. 39, 92 (1954).

${ }^{54}$ B. De Jong and G.E. Brown, Geochim. Cosmochim. Acta 44, 491 (1980).

${ }^{55}$ S.K. Lee and J.F. Stebbins, Am. Mineral. 84, 937 (1999).

${ }^{56}$ X. Yuan and A.N. Cormack, Comput. Mater. Sci. 24, 343 (2002).

${ }^{57}$ J. Du and Y. Xiang, J. Non. Cryst. Solids 358, 1059 (2012).

${ }^{58}$ J. Du, J. Am. Ceram. Soc. 92, 87 (2009). 


\section{Appendix:}

The atomic charges of sodium boroaluminosilicate glasses calculated from the current model is shown in Table 1. The compositions of the sodium borosilicate glasses simulated and comparison of the simulated percentage of four coordinated B and those from the Yun, Dell and Bray model $^{10,11}$ are listed in Table 2.

The pair distribution function plots and the cutoffs for Si-O, B-O and Al-O pairs in all simulation SBNA compositions as well as the chosen cutoff values are shown in Figure 1. 
Table 1 Atomic charges for sodium boroaluminosilicate glasses $16 \mathrm{Na}_{2} \mathrm{O}-4 \mathrm{xAl}_{2} \mathrm{O}_{3}-4 \mathrm{yB}_{2} \mathrm{O}_{3}-4(21$ $\mathrm{x}-\mathrm{y}) \mathrm{SiO}_{2}(\mathrm{x}=1,2,3,4$ and $\mathrm{y}=3,4,5,6)$.

\begin{tabular}{cccccc}
\hline SBNA x-y & $\mathrm{Si}$ & $\mathrm{B}$ & $\mathrm{Al}$ & $\mathrm{O}$ & $\mathrm{Na}$ \\
\hline SBNA 4-6 & 1.890626 & 1.413190 & 1.418126 & -0.94437 & 0.473126 \\
SBNA 3-6 & 1.885460 & 1.448099 & 1.412960 & -0.94954 & 0.467960 \\
SBNA 3-5 & 1.885762 & 1.451831 & 1.413262 & -0.94924 & 0.468262 \\
SBNA 3-4 & 1.886289 & 1.455131 & 1.413789 & -0.94871 & 0.468789 \\
SBNA 3-3 & 1.886955 & 1.458586 & 1.414455 & -0.94804 & 0.469455 \\
SBNA 2-6 & 1.879532 & 1.486120 & 1.407032 & -0.95547 & 0.462032 \\
SBNA 2-5 & 1.880749 & 1.490579 & 1.408249 & -0.95425 & 0.463249 \\
SBNA 2-4 & 1.882115 & 1.495406 & 1.409615 & -0.95288 & 0.464615 \\
SBNA 2-3 & 1.883536 & 1.502450 & 1.411036 & -0.95146 & 0.466036 \\
SBNA 1-6 & 1.873734 & 1.521426 & 1.401234 & -0.96127 & 0.456234 \\
SBNA 1-5 & 1.876112 & 1.524443 & 1.403612 & -0.95889 & 0.458612 \\
SBNA 1-4 & 1.878437 & 1.528907 & 1.405937 & -0.95656 & 0.460937 \\
SBNA 1-3 & 1.881038 & 1.532320 & 1.408538 & -0.95396 & 0.463538 \\
\hline
\end{tabular}

Table 2 Sodium borate glass compositions and comparison of average B coordination number from simulation and those from Dell-Bray model prediction. The "SBN-a" and "SBN-b" glasses are with $\mathrm{K}=1$ and $\mathrm{K}=2$, respectively.

\begin{tabular}{lccccccc}
\hline & & & & \multicolumn{5}{c}{ Average B coord. number } \\
\hline & $\mathrm{SiO}_{2} \mathrm{~mol} \%$ & $\mathrm{Na}_{2} \mathrm{O} \mathrm{mol} \%$ & $\mathrm{~B}_{2} \mathrm{O}_{3} \mathrm{~mol} \%$ & $\rho\left(\mathrm{g} / \mathrm{cm}^{3}\right)$ & This (MD) & YDB model & Diff. (\%) \\
SBN-a0 & 69.5 & 0.0 & 30.5 & 2.042 & 3.03 & 3.00 & -0.99 \\
SBN-a3 & 48.0 & 3.3 & 48.7 & 2.069 & 3.07 & 3.07 & 0.00 \\
SBN-a10 & 44.4 & 9.6 & 46.1 & 2.181 & 3.22 & 3.21 & -0.31 \\
SBN-a12 & 59.7 & 12.2 & 28.1 & 2.370 & 3.41 & 3.44 & 0.88 \\
SBN-a13 & 75.0 & 12.5 & 12.5 & 2.780 & 3.91 & 3.87 & -1.02 \\
SBN-a14 & 67.7 & 14.2 & 18.1 & 2.450 & 3.75 & 3.73 & -0.53 \\
SBN-a30 & 55.3 & 30.0 & 14.7 & 2.540 & 3.58 & 3.62 & 1.12 \\
SBN-b20 & 45.5 & 9.1 & 45.5 & 2.161 & 3.19 & 3.20 & 0.31 \\
SBN-b30 & 43.5 & 13.0 & 43.5 & 2.261 & 3.30 & 3.30 & 0.00 \\
SBN-b40 & 41.7 & 16.7 & 41.7 & 2.350 & 3.43 & 3.40 & -0.87 \\
SBN-b50 & 40.0 & 20.0 & 40.0 & 2.429 & 3.56 & 3.50 & -1.69 \\
SBN-b60 & 38.5 & 23.1 & 38.5 & 2.480 & 3.66 & 3.56 & -2.73 \\
\hline
\end{tabular}




\begin{tabular}{llllllll}
\hline SBN-b70 & 37.0 & 25.9 & 37.0 & 2.499 & 3.71 & 3.56 & -4.04 \\
SBN-b90 & 34.5 & 31.0 & 34.5 & 2.518 & 3.50 & 3.53 & 0.86 \\
SBN-b100 & 33.3 & 33.3 & 33.3 & 2.536 & 3.54 & 3.50 & -1.13 \\
SBN-b120 & 31.3 & 37.5 & 31.3 & 2.561 & 3.57 & 3.45 & -3.36 \\
SBN-b130 & 30.3 & 39.4 & 30.3 & 2.560 & 3.56 & 3.43 & -3.65 \\
SBN-c10 & 64.5 & 3.2 & 32.3 & 2.098 & 3.09 & 3.10 & 0.32 \\
SBN-c20 & 62.5 & 6.3 & 31.3 & 2.147 & 3.17 & 3.20 & 0.95 \\
SBN-c30 & 60.6 & 9.1 & 30.3 & 2.237 & 3.27 & 3.30 & 0.92 \\
SBN-c40 & 58.8 & 11.8 & 29.4 & 2.308 & 3.39 & 3.40 & 0.29 \\
SBN-c50 & 57.1 & 14.3 & 28.6 & 2.396 & 3.52 & 3.50 & -0.57 \\
SBN-c60 & 55.6 & 16.7 & 27.8 & 2.450 & 3.65 & 3.60 & -1.37 \\
SBN-c70 & 54.1 & 18.9 & 27.0 & 2.480 & 3.71 & 3.63 & -2.16 \\
SBN-c90 & 51.3 & 23.1 & 25.6 & 2.517 & 3.80 & 3.63 & -4.47 \\
SBN-c100 & 50.0 & 25.0 & 25.0 & 2.530 & 3.83 & 3.63 & -5.22 \\
SBN-c110 & 48.8 & 26.8 & 24.4 & 2.518 & 3.52 & 3.60 & 2.27 \\
SBN-c120 & 47.6 & 28.6 & 23.8 & 2.521 & 3.53 & 3.58 & 1.42 \\
SBN-c130 & 46.5 & 30.2 & 23.3 & 2.526 & 3.56 & 3.56 & 0.00 \\
\hline
\end{tabular}
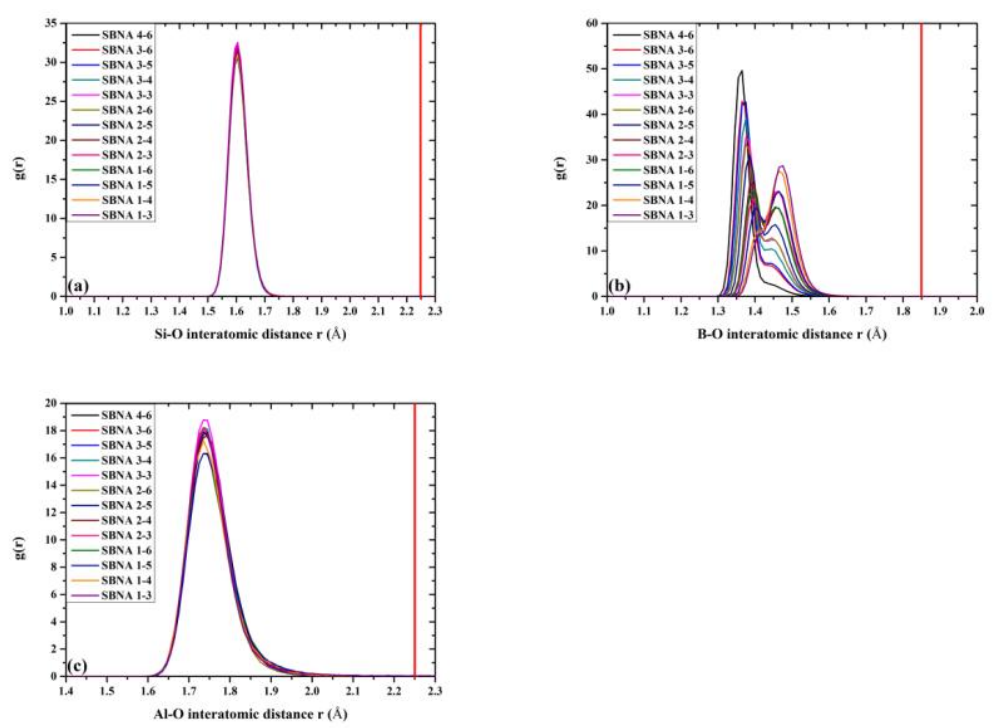

Figure 1 Pair distribution function plots and the cutoffs for a) $\mathrm{Si}-\mathrm{O}$, b) B-O and c) Al-O pairs in all the SBNA compositions, respectively. The position of the red vertical line is the cutoff value we chose for each pair. 